\title{
Nanoparticles in Biomedicine-Focus on Imaging Applications
}

\author{
Peng Zhou ${ }^{2 *}$, Juping Wang ${ }^{3 *}$, Xiaohong $\mathrm{Du}^{5}$, Tao Huang ${ }^{6}$, Prakash D. Nallathamby ${ }^{7}$, Lan Yang ${ }^{1}$, Weiwei Zou', Yongchao Zhou ${ }^{1}$, Jean-
} Michel Jault ${ }^{8}$, Song Chen ${ }^{4, *}$ and Feng Ding ${ }^{1, *}$

Over the last two decades, nanotechnology has become one of the most dynamically evolving field of research. Various types of nanoparticles are widely exploited to extend our understanding of biological interactions at the molecular level. They are actively engaged in the biomedical research for imaging, biosensing, drug delivery and/or concurrent therapy. Recent progress on this field is briefly reviewed here with an emphasis placed on the wide imaging applications of nanoparticles. Collectively, this field will no doubt make greater impact after we gradually address any potential risks of nanoparticles.

Keywords: Nanoparticles; Biomedical application; Imaging; Biosensing; Drug delivery; Therapy

Received 18 November 2018, Accepted 26 January 2019

DOI: $10.30919 / \mathrm{es} 8 \mathrm{~d} 708$

\section{Introduction}

Originally coming from Richard Feynman's lecture There's plenty of room at the bottom in 1959, the term "nanotechnology" generally describes the development, reduction, modification, or fabrication of materials at nanoscale with unique properties different from their bulk counterparts. ${ }^{1}$ The development of Scanning Tunneling Microscope (STM) and the Atomic Force Microscope (AFM) in the 1980s powered the modern development of nanotechnology. ${ }^{2,3}$ Next, the discovery of fullerene in 1985 and successful synthesis of carbon nanotubes in 1991

${ }^{1}$ Department of Microbiology \& Immunology, School of Basic Medical Sciences, Wenzhou Medical University, Wenzhou 325035, China

${ }^{2}$ Department of Anatomy, School of Basic Medical Sciences, Wenzhou Medical University, Wenzhou 325035, China

${ }^{3}$ Department of Pathophysiology, School of Basic Medical Sciences, Youjiang Medical University for Nationalities, Baise, Guangxi 533000, China

${ }^{4}$ Institute of Medicinal Biotechnology, Jiangsu College of Nursing, Huaian, Jiangsu 223005, China

${ }^{5}$ Center of Systems Medicine, Institute of Basic Medical Sciences, Chinese Academy of Medical Sciences and Peking Union Medical College, Beijing 100005; Suzhou Institute of Systems Medicine, Suzhou, Jiangsu 215123, China.

'Department of Chemistry, Savannah State University, Savannah, GA31404, USA

Department of Aerospace and Mechanical Engineering, University of Notre Dame, Notre Dame, IN 46556, USA

${ }^{8}$ UMR5086 CNRS/UCBLyon I, MMSB-IBCP, 7 Passage du Vercors 69367 Lyon cedex 07, France

\#-equal contribution

*E-mail: fding001@yahoo.com; biocs@163.com signified the dawning of a new era of nanotechnology., ${ }^{4}$ In 2003, we witnessed the first application of nanomaterials for treating cancer, ${ }^{6}$ and in the last decade researchers were thrilled at the rapid and wide increase in the biomedical applications of nanoparticles (NPs), including bioimaging of cell or tissues, clinical imaging, biosensing, diagnosis, targeted drug delivery and/or concurrent therapy.

In this work, we shall discuss the recent advances in the biomedical applications of NPs. An emphasis will be placed on biomedical imaging applications of NPs such as quantum dots (QDs), noble metal gold/silver NPs, magnetic or super-magnetic iron oxide NPs and so on. Other application of NPs for biosensing, diagnosis, drug delivery and/or therapy will also be briefly mentioned. Next, we will touch briefly on the potential toxicities that those NPs might cause in an introduced system. Finally, we will wrap it up by summarizing the general conclusions we arrived on the current status and pointed out the future directions of biomedical research of these NPs.

\section{Biomedical applications of NPs}

Nps are nano-sized objects with size usually ranging between 1 and 100 $\mathrm{nm}$. At the nanometer scale, they exhibited distinct physical or chemical properties which are dramatically different from their bulk forms. Owing to these unique characteristics, they were increasingly applied in many biomedical fields such as Bio- or clinical imaging, drug delivery, and/or concurrent therapy. Applications of NPs in biomedical imaging include QDs based fluorescent imaging, optical imaging via gold ( $\mathrm{Au})$ and silver (Ag) NP probes, Magnetic Resonance Imaging (MRI) based on magnetic NPs, and etc. Regarding NPs facilitated drug delivery and / or concurrent therapy, heat ablation of target tumors as well as targeted delivery of anticancer or other therapeutic reagents are of intense interest to researchers in the field of nanomedicine. Fig. 1 summarizes the attributes of multifunctional NPs that have attracted the field of bioimaging and medicines. 


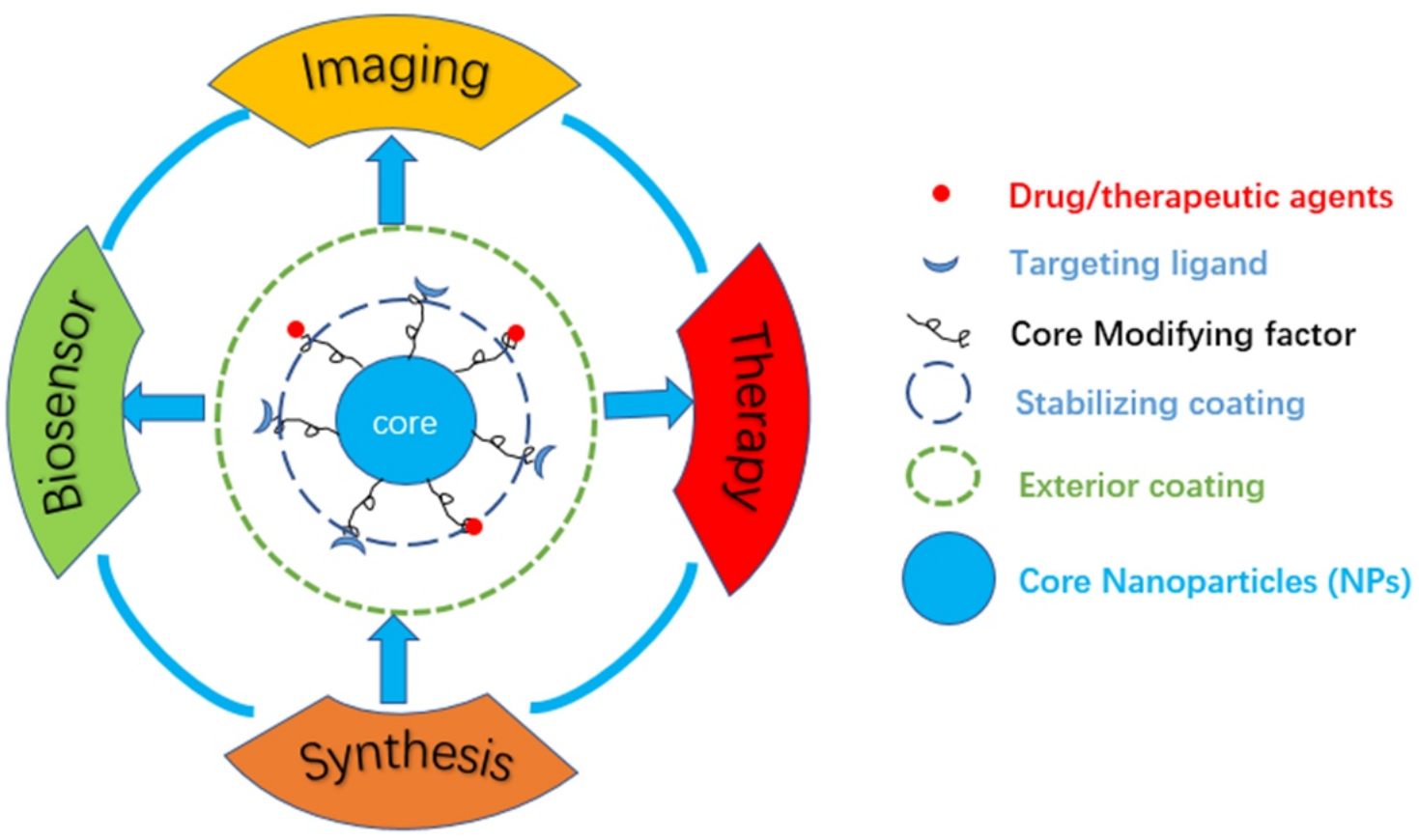

Fig. 1 Schematic representations of biomedical applications of multifunctional NPs.

\subsection{Imaging applications of NPs}

The last two decades have witnessed the increasing advances in imaging applications of NPs. QDs have arisen as popular imaging nanoprobes and gathered much interest from scientists in the field of biomarkers or biosensors due to their superior photostability, broad excitation wavelength and narrow range of emission, as well as multiple possibilities of surface modification. ${ }^{7-9}$ Other classes of NPs such as noble metal (gold/silver) $\mathrm{NPs}^{10-14}$ and metal oxide NPs ${ }^{15-18}$ also found their greater applications in bio- and clinical imaging as contrast agents for cell labeling and tracking, labeling transplants, grafts and organs. Because of their smaller size comparable to that of biomolecules (DNA, RNA, virus, antibody, etc.), high quantum yields, these NPs start to emerge as the next generation imaging probes and will bring more impact into the imaging fields in the short future. ${ }^{19}, 20$ Other than that, silica NPs, molecular dots, carbon-based NPs, biological NPs, polymer nanospheres, and liposomes are also widely utilized for bio- or clinical imaging.

\subsubsection{NPs for optical and fluorescent imaging}

Semiconductor QDs are the mostly used NPs for efficient labeling of biomolecules and tissues in fluorescent imaging owing to their sizedependent optical properties such as their controllable size and shape, much higher quantum yields ( $\sim 100$ times brighter than traditional fluorescent probes) and longer fluorescence lifetime, broader excitation and narrower emission spectra compared to organic dye molecules, multiplexed color imaging from tunable emission spectra with single excitation. $^{7-9,21,22}$ Recent advances in conjugating QDs particle surface with biomolecules enabled cell specific targeting. ${ }^{23-25}$ Martynenko and coworkers reviewed the latest progress on the application of the semiconductor QDs in bioimaging and biosensing (Fig. 2). ${ }^{25}$ Structures of this type, composed of a $\mathrm{CdSe}^{26}$ and $\mathrm{InP}^{27}$ cores, have been used in imaging KB cells. Patra et al. developed a dual-functional QDs developed by synthesis of magnetic iron-cobalt NPs coated with gold functioning as an inhibitor of proangiogenic VEGF-165 while the core part allowed MRI. ${ }^{28}$ However, despite their popularity in biomedical imaging, targeting cell with QDs is often confronted with critical issues in their cellular internalization as larger sized QDs many interfere with protein trafficking and the viability of the cells. Thus, researchers have to balance between getting bright signals by putting enough number of NPs into the cell and keeping their toxicity to the cells at the minimum, a possible solution to this dilemma was proposed by using a two-photon microscope and up to date, this remains an open challenge. Other multiplexed QDs conjugated with biomolecules such as antibodies recognizing a specific receptor on cancerous cells has enabled specific tumor targeting in vivo. ${ }^{29,30}$ Meanwhile, fluorescent QDs have also shown great potentials in imaging of lymphatic or cardiovascular systems or stem or progenitor cells. ${ }^{31-33}$ Since in vivo tissue imaging requires high quantum efficiency of QDs to penetrate deep enough into the tissue or organs. To accomplish this, near IR (infrared) emitting QDs seems to be an optimal probe which not only gives longer emission (Em) wavelength required for deep penetration of targets but also minimized the intrinsic autofluorescence from the background in the shorter wavelength. ${ }^{34,35}$ For instance, a few research groups reported imaging of sentinel lymph systems by using near infrared emitting QDs, which enabled the surgeons to quickly locate the target. ${ }^{36}$ Coronary vasculature of a rat heart has been imaged with near IR emitting NPs with high sensitivity, ${ }^{37}$ which together with the stability of fluorophore is often a challenge in cardiovascular imaging.

It is also worth mentioning that QDs have recently been applied for some super-resolution fluorescence microscopy techniques. For instance, QDs was widely employed as long-term monitoring cell markers in NSOM (near field super-resolution optical microscopy, one of the super-resolution techniques). For single-molecule detection on cell membranes using NSOM/QDs, QDs are first immunostained with monoclonal antibodies via biotin-streptavidin strategy and then conjugated with antigens as depicted in Fig. $3 .^{38}$ Fan et al. applied NSOM/QDs to study the nanoscale relationship between CD4 and CD25 of $\mathrm{T}$ cells by dual color fluorescent labeling of CD4 and CD25 

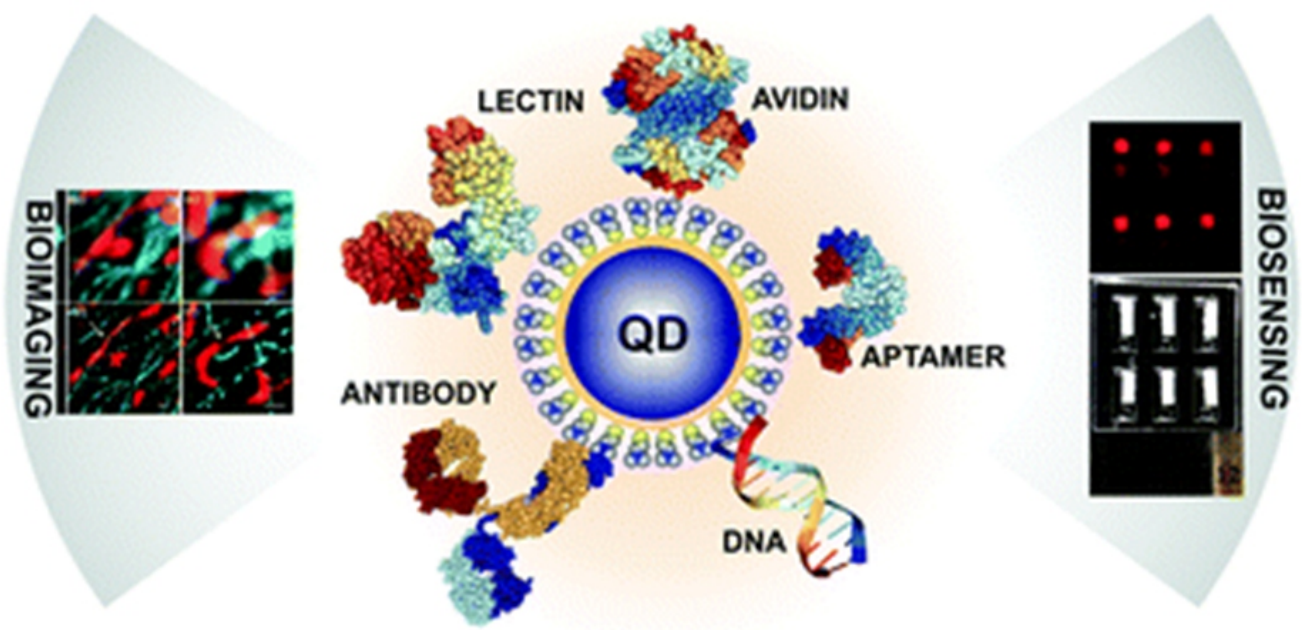

Fig. 2 Graphical abstract of QDs conjugated with different types of biomolecules for bioimaging and biosensing. (Reprinted with permission from Ref. [25]. Copyright 2017, Royal Society of Chemistry.)

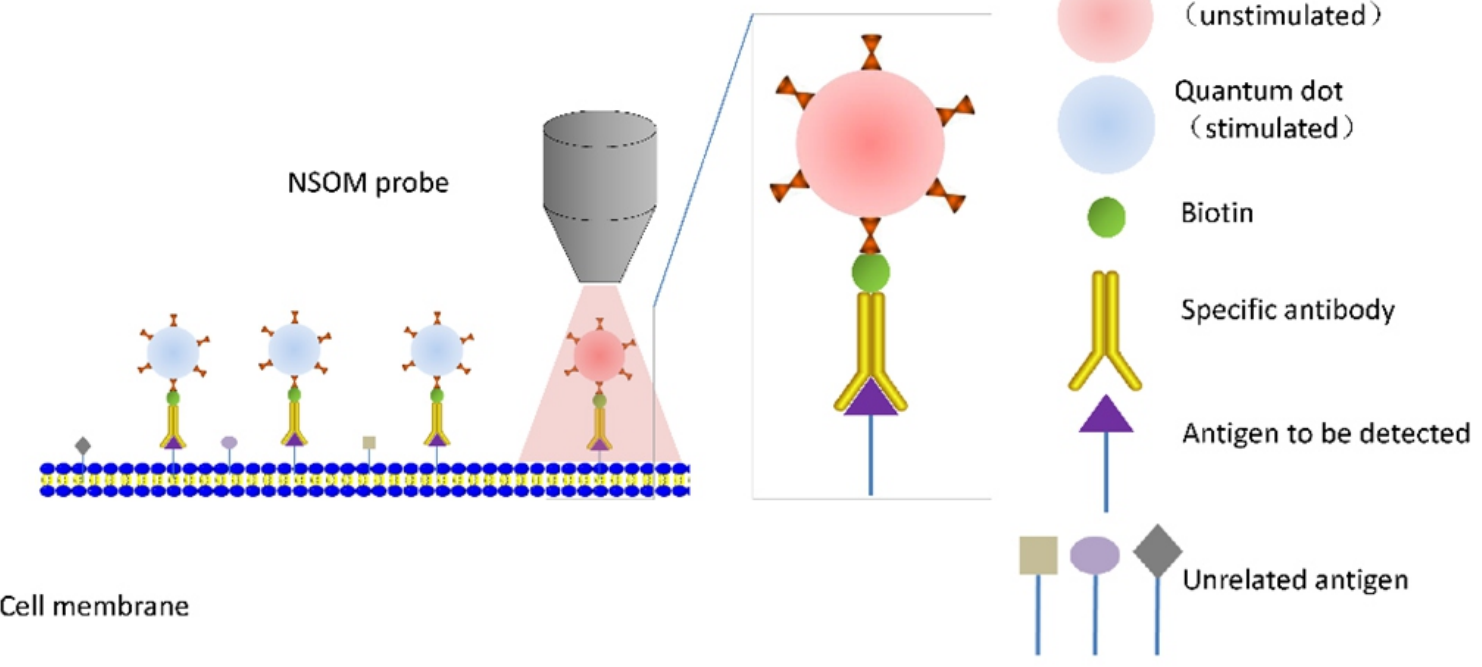

Fig. 3 Schematic depiction of NSOM/QD based labeling. (Adopt from Fig. 1 in Ref. [38]. Copyright 2010, Elsevier.)

with QD655 and QD605, respectively (Fig. 4). ${ }^{39}$ In regard to application of QDs in far field super resolution approaches like STED, SIM, STORM, etc., Kne'r group described a multicolor 3D super resolution imaging reaching $24 \mathrm{~nm}$ lateral and $37 \mathrm{~nm}$ axial resolution by combining CdSe QDs' spectral blueing technique with STORM optics (Fig. 5). ${ }^{40}$

Apart from QDs, other types of NPs labeled with fluorescent dyes such as FITC, RITC are also widely used in bioimaging. ${ }^{41,}{ }^{42}$ In vivo imaging of cancer cell by fluorescent NPs have been achieved and reported on many occasions. ${ }^{4345}$ This is often done by injecting animal model targets with NPs pre-labeled cancer cells. Intrinsic to fluorescent molecules, these types of fluorescent nanoprobes suffer from photobleaching and photo-blinking problems which make them less popular than QDs. Theoretically speaking, QDs involved imaging process also needs to deal with those problems though QDs have excellent photoluminescent properties, especially if you intend to image live cells for a long-time period. In addition, it is well known that binary QDs composed of cadmium/serenide that is deleterious to cells have to be covered with a thicker surface and that make them almost twice as thick as the initial core size which limits their applications in a cell to some degree. It is worthy of mentioning the photoblinking behavior of binary QDs will hinder the tracking of biomolecules labeled with them inside a biosystem. ${ }^{46-48}$ A possible alternative could be by using noble metal NPs (gold/silver). Due to its relative biocompatibility and simplicity in the synthesis and size-dependent surface plasmon resonance, Au NPs have also been an excellent choice for near IR 


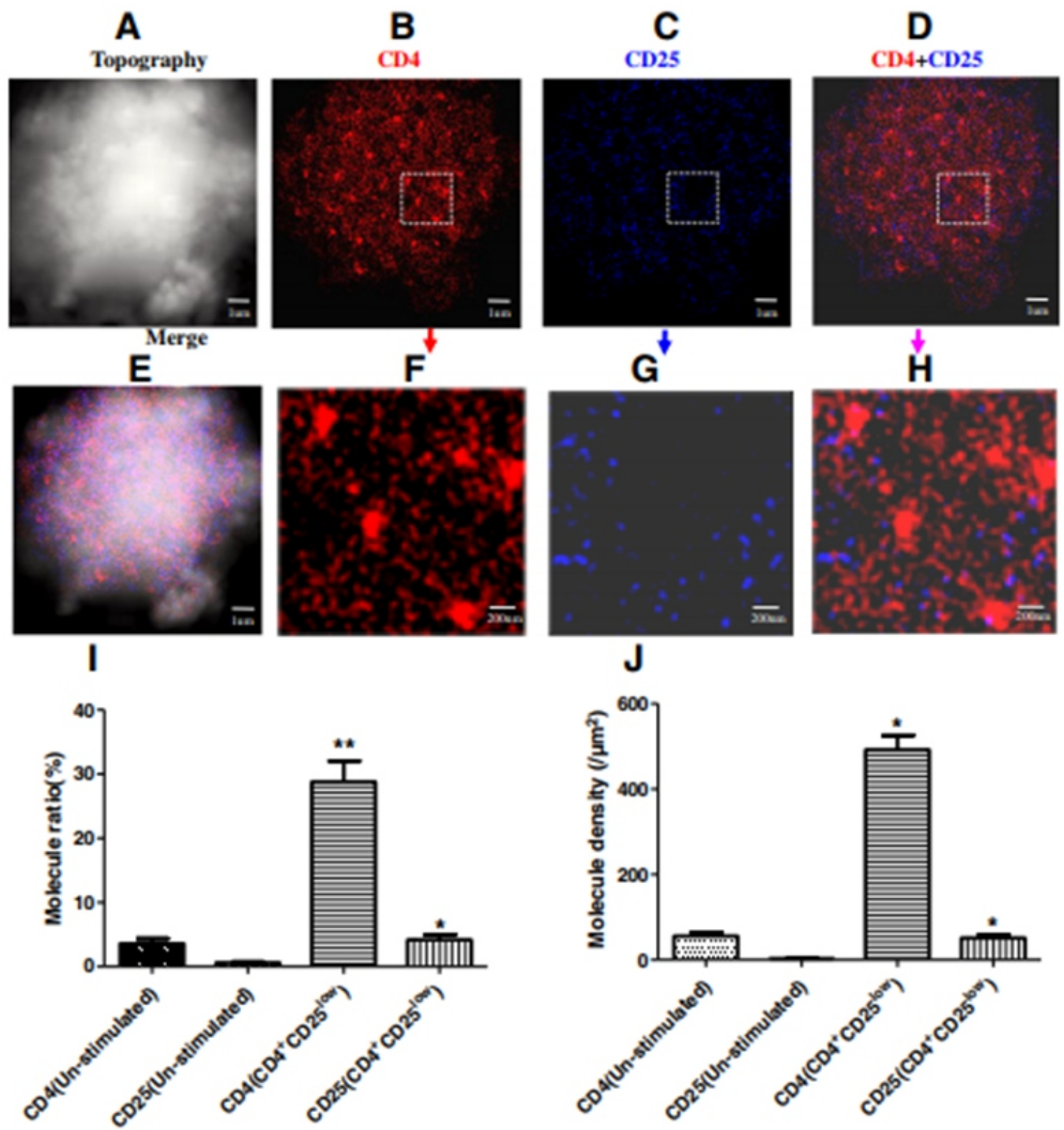

Fig. 4 Simultaneous nanoscale dual-color imaging of CD4 and CD25 on the surface of CD4+CD25low T cells through using NSOM/QD system. a T cell topography. b Fluorescence image of CD4 labeled with QD-655 (red). c Fluorescence image of CD25 labeled with QD-605 (blue). d Merge of CD4 and CD25 two color fluorescence images. e Merge of cell topography and two color fluorescence images. $\mathrm{f}-\mathrm{h}$ Zoom images of the areas as indicated by the squares on $(b-d)$, respectively. $i$ The percentage numbers of CD4 or CD25 molecules arrayed to form nanodomains. $j$ Molecule density of CD4 or CD 25 nanodomains. Data were expressed as mean \pm SEM in (i, j), ${ }^{*} \mathrm{P}<0.02,{ }^{*} * \mathrm{P}<0.01$ (i) and $* \mathrm{P}<0.01$ (j) compared with control. (Reprinted with permission from Ref. [39]. Copyright 2015, Springer.)

emitting bioimaging. ${ }^{49}, 50$ A few imaging technologies have made Au NPs or their derivatives possible in bioimaging. For instance, the photoacoustic imaging makes thermal expansion and sound wave detectable by a pulse of near IR. ${ }^{51}$ Another methodology called Optical Coherence Tomography (OCT) utilized the increased scattering of Au nanoshells at the tumor site for contrasted in vivo imaging. 52,53 Meanwhile, since gold nanomaterials possess the strong surface plasmon resonance, it can increase the occurrence rate of two photon excitations and relaxation of energy through fluorescence, and it adapted gold nanomaterials for in vivo imaging by two-photon fluorescence spectroscopy. Aside from those imaging techniques mentioned above,
Raman spectroscopy with enhanced Raman effects of reporter dyes at the surface of $\mathrm{Au}$ NPs has also been shown to precisely locate them in animal models. ${ }^{54,55}$

Though a little bit less popular than their gold counterparts, $\mathrm{Ag}$ NPs were also found very useful in the imaging field. Compared to $\mathrm{Au}$ NPs, the surface modified Ag NPs or bare Ag NPs have even stronger size-dependent localized surface plasmon resonance (LSPR) and much higher and stable quantum yields, which make them ideal nanoprobes for tracking biological events in live cells in real time without showing photobleaching or photo-blinking. For instance, $\mathrm{Xu}$ group researchers have applied Ag or Au NPs based multi-colored optical nanoprobe (Fig. 6) 
(A) 705nm QD

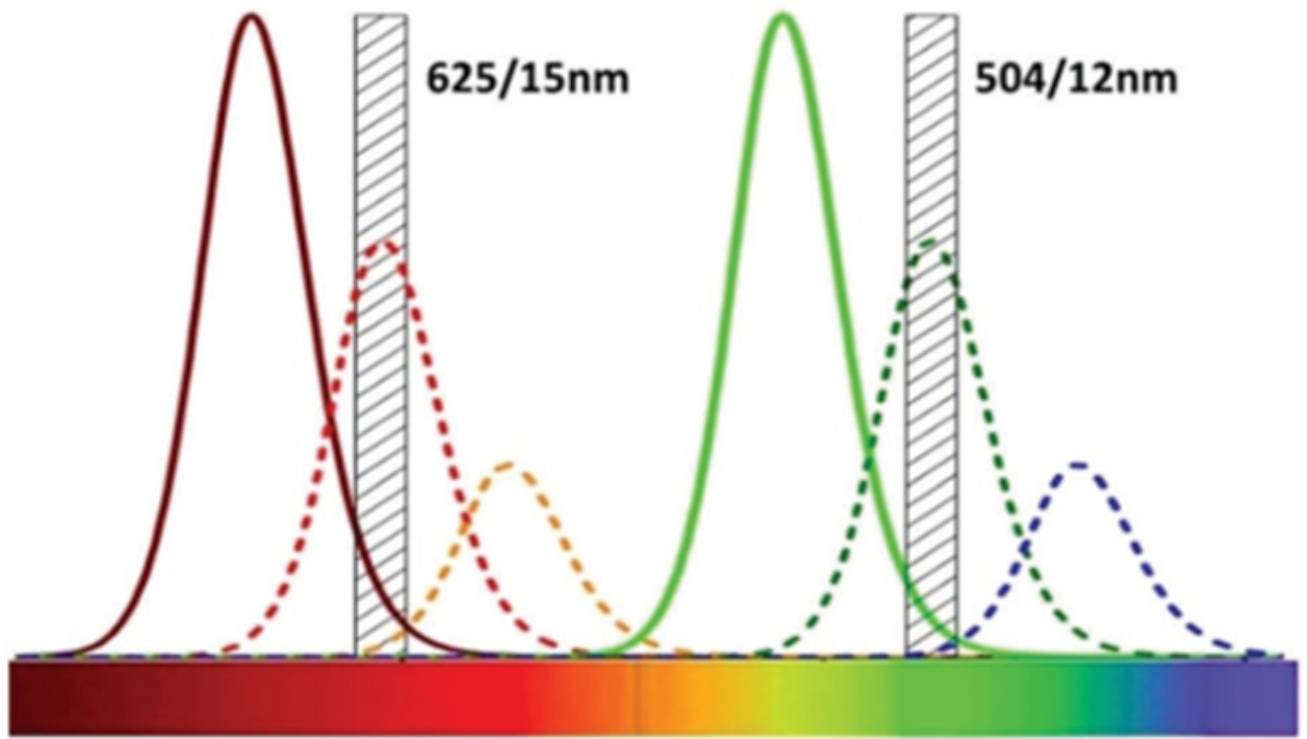

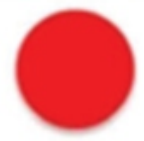
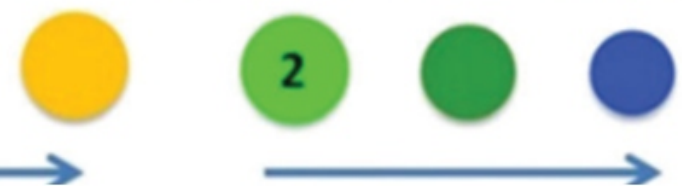

(B)
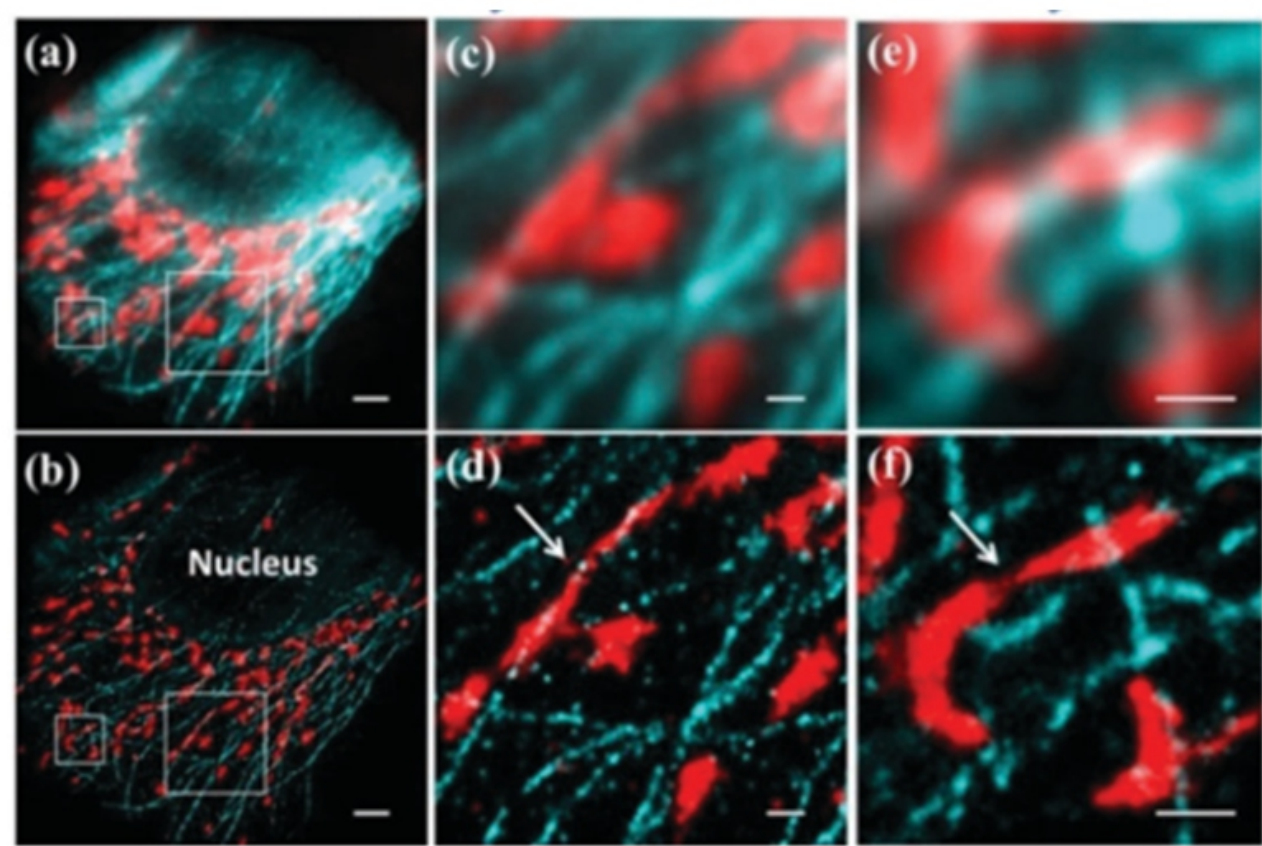

Fig. 5 (A) Principle of multicolor blueing and (B) (a-e) two-color STORM images of microtubules and mitochondria labelled with two sizes of CdSe QDs - QD $705 \mathrm{~nm}$ and QD $565 \mathrm{~nm}$. The QDs shift up to approximately $80 \mathrm{~nm}$, after which the QDs are completely photobleached. The $705 \mathrm{~nm}$ QDs will be photooxidized and stochastically emit in the $625 \mathrm{~nm}$ passband but will no longer emit when they reach the $504 \mathrm{~nm}$ passband, which detects the $565 \mathrm{~nm}$ QDs. Thus, both colors can be simultaneously detected without cross-talk. (a and b) Wide-field and STORM images, respectively. Scale bars are $2 \mathrm{~mm}$. (c and d) Magnified images of the boxed region on the right in (a and b). Scale bars are $500 \mathrm{~nm}$. (e and f) Magnified images of the boxed region on the left in ( $\mathrm{a}$ and b). Scale bars are $500 \mathrm{~nm}$. (Reprinted with permission from ref. [40]. Copyright 2015, American Chemical Society.) 

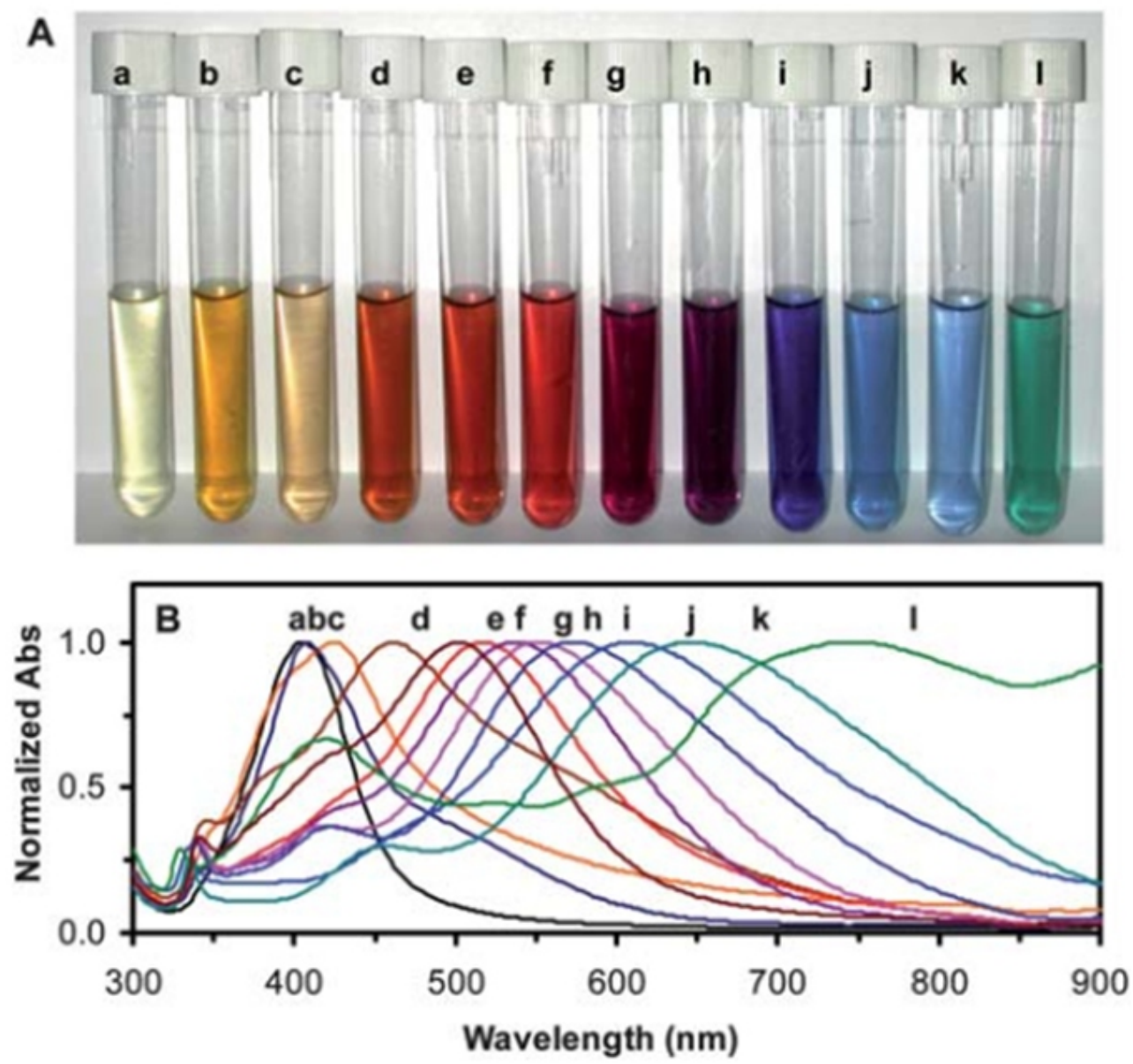

Fig. 6 Study of absorption and scattering plasmonic optical properties of colloidal Ag NPs using UV-vis absorption spectroscopy. (A) Photos of colloids show: (a) light yellow; (b) yellow; (c) light orange; (d) orange-red; (e) red; (f) dark red; (g) purple; (h) purple violet; (i) violet; (j) blue; (k) light blue; and (l) green colors. (B) Normalized absorbance of UV-vis absorption spectra of the colloids of Ag NPs in (A) shows the peak wavelength (max) with FWHM at: (a) $393 \mathrm{~nm}(64 \mathrm{~nm})$; (b) $405 \mathrm{~nm}$ (69nm) with a weak shoulder peak at $526 \mathrm{~nm}$; (c) $427 \mathrm{~nm}$ (110 nm) with a weak shoulder peak at $364 \mathrm{~nm}$; (d) $461 \mathrm{~nm}(192 \mathrm{~nm}$ ) with a weak shoulder peak at $382 \mathrm{~nm}$; (e) $502 \mathrm{~nm}(160 \mathrm{~nm}$ ) with two weak shoulder peaks at $422 \mathrm{and} 342 \mathrm{~nm}$; (f) $518 \mathrm{~nm}$ (146 $\mathrm{nm})$ with two weak shoulder peaks at 430 and $340 \mathrm{~nm}$; (g) $536 \mathrm{~nm}(158 \mathrm{~nm})$ with two shoulder peaks at 418 and $340 \mathrm{~nm}$; (h) $552 \mathrm{~nm}(166 \mathrm{~nm})$ with two shoulder peaks at 414 and $340 \mathrm{~nm}$; (i) $572 \mathrm{~nm}(172 \mathrm{~nm})$ with two shoulder peaks at 416 and $338 \mathrm{~nm}$; (j) $606 \mathrm{~nm}$ (212 nm) with a shoulder peak at $334 \mathrm{~nm}$; (k) $646 \mathrm{~nm}(215 \mathrm{~nm})$ with two shoulder peaks at 450 and $336 \mathrm{~nm}$; and (1) $738 \mathrm{~nm}(130 \mathrm{~nm})$ with two shoulder peaks at $420 \mathrm{~nm}$ (78 nm) and $330 \mathrm{~nm}$. (Reprinted with permission from Ref. [56] . Copyright 2010, Royal Society of Chemistry.)

with these unique optical properties for live cell imaging of efflux function of $\mathrm{ABC}$ in $B$. subtilis ${ }^{57-62}$ or MexABM transporter in $P$. aeruginosa $^{63-65}$ or cancer stem cells, ${ }^{66-68}$ mapping receptor-ligand interactions in live cells in real time ${ }^{69}$ or tracking the real-time process of apoptosis mediated by TNF-TNFR pathway. Notably, Lee et al. utilized well synthesized and characterized monodisperse $\sim 12 \mathrm{~nm} \mathrm{Ag}$ NPs to mimic the substrate of efflux transporter BmrA in B. subtilis and imaged the transport of Ag NPs in and out of living bacterial cells in real-time. ${ }^{57}$ Also based on these characteristics, they further developed a super high resolution imaging technique named PHOTON which can reach several $\mathrm{nm}$ in resolution and this PHOTON imaging platform enabled the uncovering of many important molecular events in a biosystem such as individual ligand-receptor binding (Fig. 7) ${ }^{70}$ or TNFTNFR mediated apoptosis (Fig. 8) ) $^{71}$ that is beyond the capacity of normal confocal fluorescence microscopy. ${ }^{72-75}$ Compared to the very costly superhigh resolution microscopy such as STORM, STED, PHOTON is much cost-effective and user-friendly, which thus deserves more wide applications.
Due to its chemical and biological inertness and thermal stability, Silica is found to be very suitable for developing biodegradable coreshell hybrid structured NPs. High stability due to the charged surface, easy accomplishment of modification of the surface via siloxane-based cross linkers, and reactants-permeable mesoporous silica structures all make silica based nanoshells for use as biosensors, biomarkers, and other biomedical detectors. For instance, fluorophore-conjugated silica NPs had long been used as optical imaging agents with excellent photostability and high fluorescence emission intensity. ${ }^{76,77}$ To date, silica NPs doped with fluorescent dyes, fluorescent NPs, or QDs were extensively studied as optical imaging probes for various biological applications such as targeted cancer imaging in vitro and in vivo. ${ }^{77-82}$ For more reading about biomedical applications of silica NPs, please refer to several excellent reviews ${ }^{83,84}$.

Calcium phosphate NPs are biocompatible, multilayer nanocomposites that are more rigid than liposomal structures. Because of their composition, calcium phosphate NPs are usually less toxic than other types of NPs and diagnostic or therapeutic agents can be trapped 


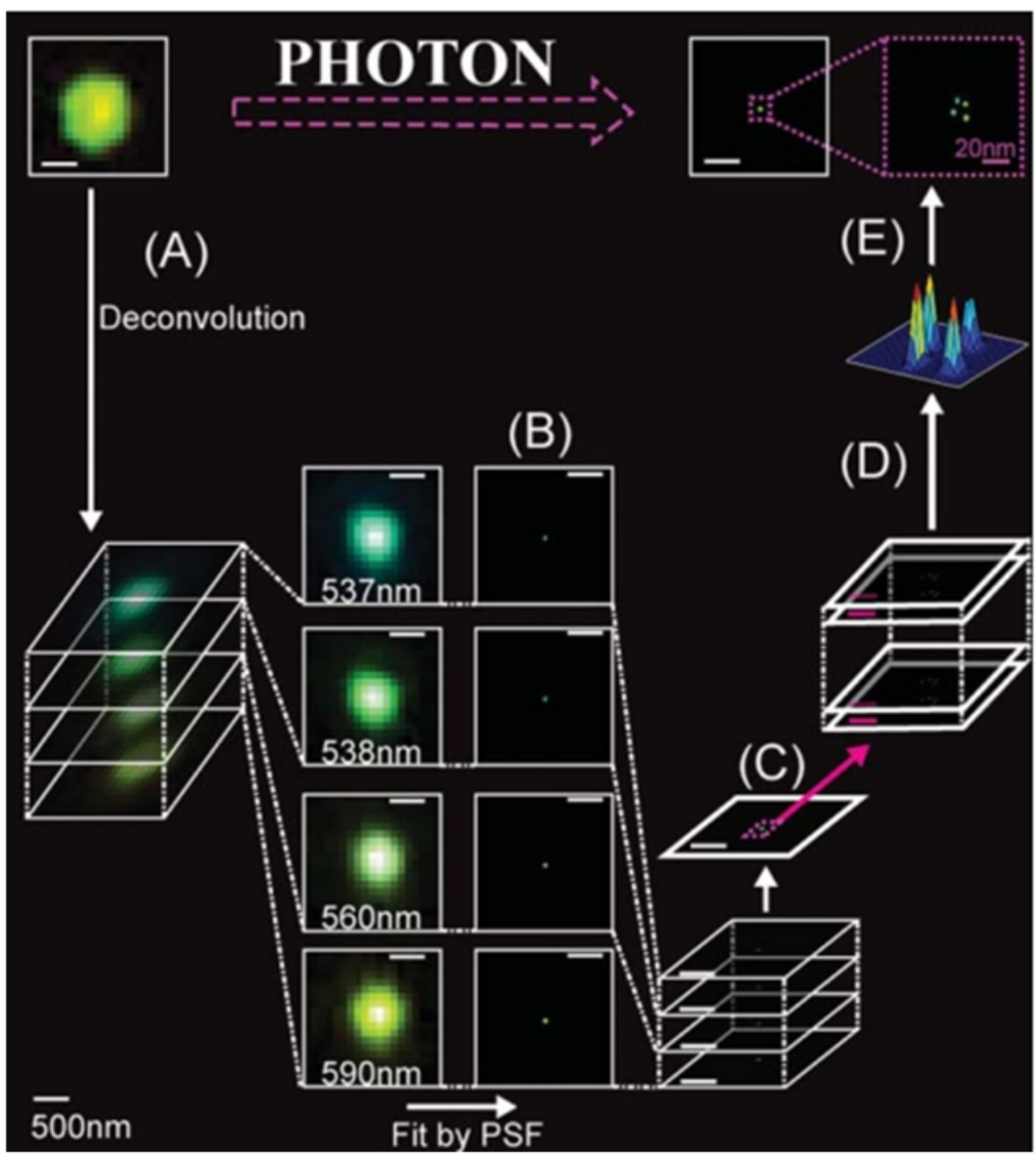

Fig. 7 Illustration of design of PHOTON for mapping individual ligands (biotin) and their binding sites with single protein molecules (streptavidin) in single protein-ligand complexes: (A) deconvolution of LSPR spectrum of single SMNOBS (AgMMUA-biotin) bound with single streptavidin molecules (AgMMUA-biotin-streptavidin NPs) using LSPR spectrum of individual SMNOBS via Cauchy-Lorentz distribution model (see ESI $\dagger$ ). (B) Determination of centroids of individual SMNOBS bound with single streptavidin molecules using PSF. (C) Multiple (20) measurements of (A-B). (D) Locating precise positions of individual SMNOBS bound with streptavidin in single complexes using 2D Gaussian fitting. (E) Assembly of (D) into super-resolution images of individual SMNOBS in the complex at $1.2 \mathrm{~nm}$ resolution. (Reprinted with permission from Ref. [70] . Copyright 2011, Royal Society of Chemistry.)

in them during synthesis, they thus could be used as universal carriers. For example, Zhang et al. reported the synthesis and utilization of multifunctional calcium phosphate hollow Janus NPs for imagingguided chemo-photothermal therapy. ${ }^{85}$ Li et al. synthesized Au Nanorod (a) polyacrylic acid/ calcium phosphate yolk-shell NPs for dual-mode imaging and simultaneous drug delivery. ${ }^{86}$

Carbon dots (CDs) are newly discovered fluorescent labeling probes with high affinity to multiple cellular structures. For instance, Khan et al. recently reported yellow-orange emissive CDs that specifically bind to nucleolus RNA, which opens up the window of opportunity for single-molecule imaging and super-resolution microscopy applications. ${ }^{87}$ In another study, Atabaev et al. developed a bimodal nanoprobe based on CDs doped with dysprosium (Dy-CDs) and showed a good colloidal stability in a water solution, strong blue- green fluorescence, and suitability for T2-weighted MRI. ${ }^{88}$ Early in 2007, Cao et al. already demonstrated the two-photon luminescence microscopy imaging of human breast cancer cells owing to bright photoluminescence from internalized CDs. ${ }^{89}$ Later on, Wang and coworkers reported magnetic iron oxide-fluorescent CDs integrated NPs featuring dual-modal imaging, near IR light responsive drug carrier and photothermal therapy. ${ }^{90}$ Liyanage et al. just reported that the use of carbon nitride quantum dots (CNQDs) to assist targeted cancer therapy. Their results showed that CNQDs selectively entered pediatric glioma cells (SJGBM2), but not normal human embryonic kidney cells (HEK293) and excitation-dependent emission of CNQDs was proved to be advantageous in the in vitro cellular studies, highlighting a great potential in selective bioimaging and drug delivery for targeted cancer therapy. ${ }^{91}$ 


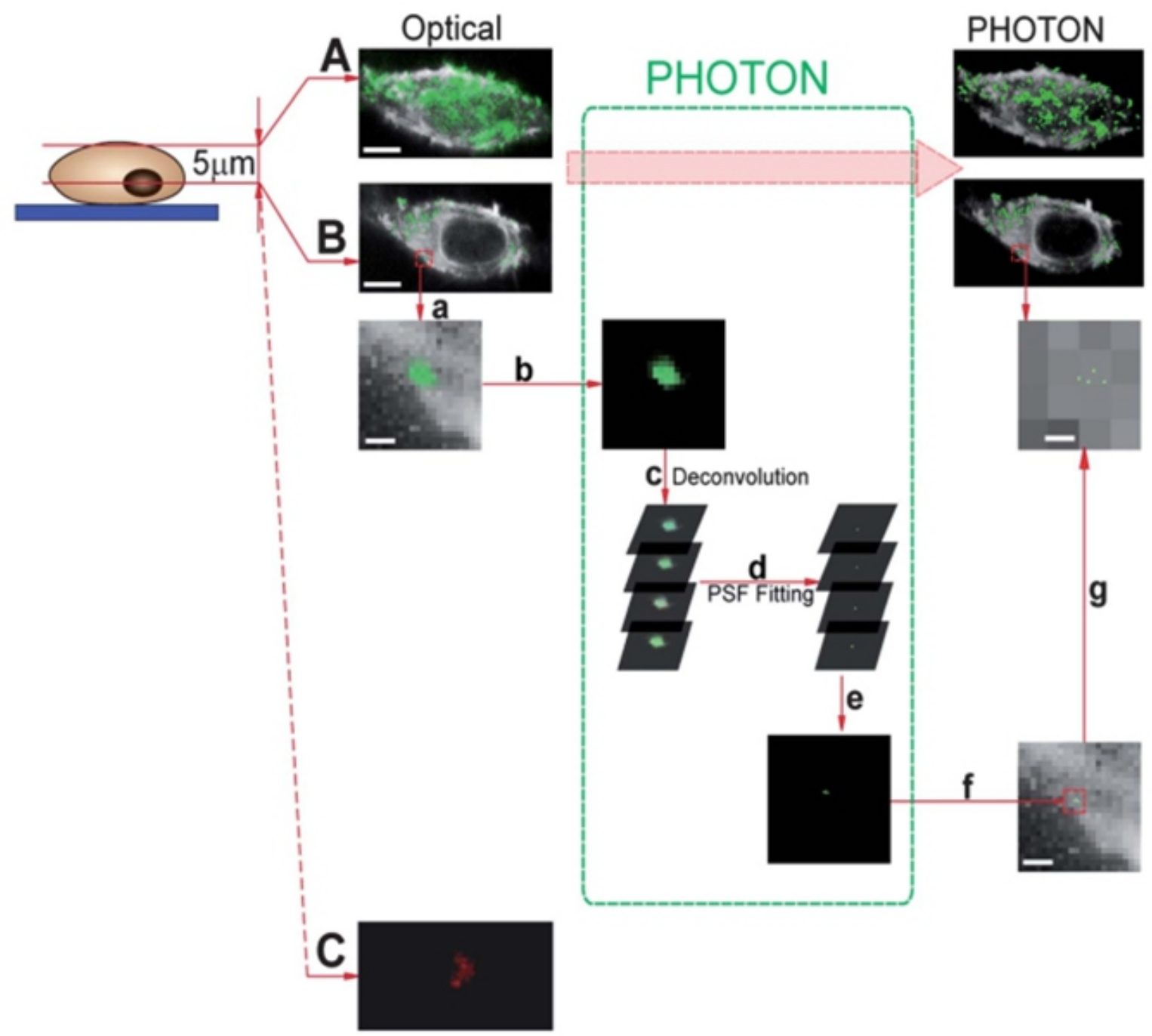

Fig. 8 Design of PHOTON for real-time super-resolution SM imaging of dynamics and mechanisms of apoptotic signaling pathways of single live cells. Dark-field optical imaging of: (A) single SMNOBS binding with TNFR1 to form single L-R complexes (bound SMNOBS) on the surface of single cells and (B) internalization of the clusters of single $\mathrm{L}-\mathrm{R}$ complexes into the cell (5 mm in-depth from the cell surface): (a) zoom-in images of that squared in (B), as an example; (b) subtraction of (a) from scattering intensity of the cellular background spectrally; (c) images of the clusters of single L-R complexes are deconvoluted using LSPR spectra of single SMNOBS, (d) which are fitted by PSF to determine the number and locations of each complex; (e) distributions of multiple (20) measurements of (c and d) are fitted by 2D-Gaussian to determine the number and precise locations of bound SMNOBS at nm resolution; (f) scattering intensity of cellular background subtracted in (b) is added back to the super-resolution images in (e); and (g) assembly of (f) into super-resolution images of individual complexes on/in single live cells. (C) Fluorescence image of Magic Red (apoptosis assay) in single cells shows intense red fluorescence, indicating the apoptotic cell. (Reprinted with permission from Ref. [71]. Copyright 2012, Royal Society of Chemistry.)

Upconversion nanoparticles (UCNPs) are endowed with unique multi-photon excitation photoluminescence properties, which make them intensively explored as novel contrast agents for biomedical imaging. Wang et al. functionalized UCNPs with a PEG grafted amphiphilic polymer and doxorubicin, folic acid, and upconversion luminiescence imaging revealed the time course of intracellular delivery of Doxorubicin by UCNPs to cancer cells with over-expressed folate acid receptors, indicating the promise of using UCNPs for multifunctional cancer imaging and/or concurrent therapy. ${ }^{92}$ Guan and colleagues reported imaging (fluorescence/upconversion luminescence/ MRI) -guided photodynamic therapy via multifunctional UCNPS-PEG$\mathrm{FA} / \mathrm{PC}_{70}$ nanocomposite. ${ }^{93}$ Zhou et al. reviewed the advances and applications of $\mathrm{UCNPs}^{94}$ and Zhang et al. discussed the application of nanodiamonds conjugated UCNPs in bio-imaging and drug delivery. ${ }^{95}$

\subsubsection{NPs for clinical imaging technologies}

Other than their applications in bioimaging as we talked above, NPs have been studied as promising contrast agents in clinical imaging such as computed tomography (CT) ${ }^{96}$ photoacoustic imaging, ${ }^{97}$ magnetic resonance imaging (MRI) ${ }^{18,98}$ and ultrasonography. ${ }^{99}$ Clinically approved contrast agents for CT are usually small iodinated molecules which suffered from a short blood half-life. For CT imaging, lipid based core structures or solid core-based or both have been studied. Au NPs have shown unique X-ray attenuation properties and it makes them the next generation contrast agents given the ease of surface modification on them. For instance, researchers reported that Au-HDL NPs were used to 


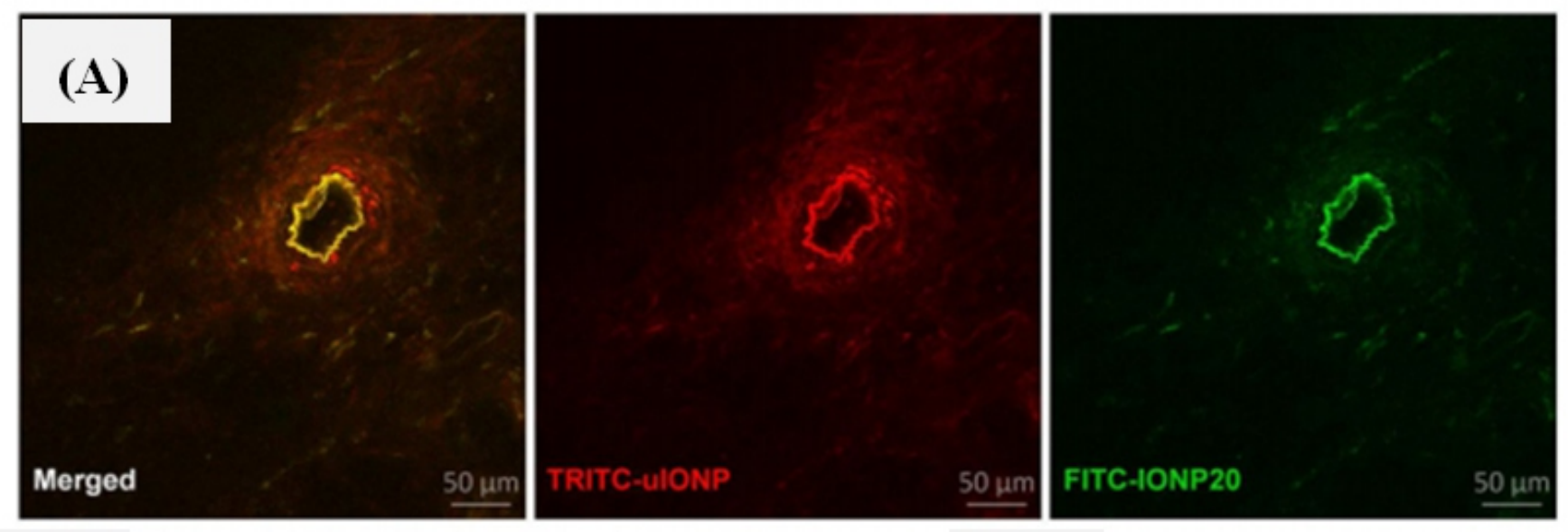

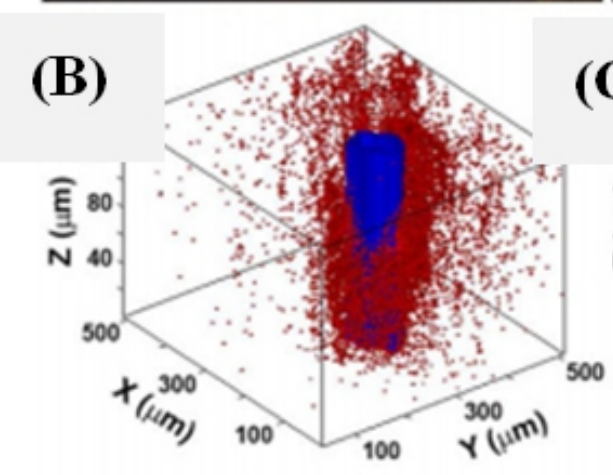

TRITC-UIONP
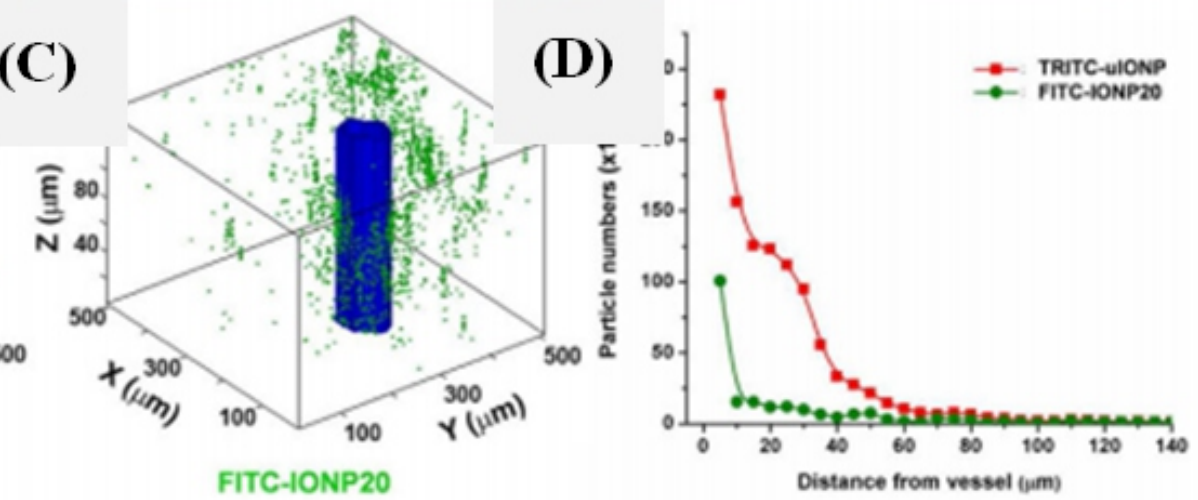

Fig. 9 (A) Multiphoton images of TRITC-uIONP (red) and FITC-IONP20 (green) distributions in the tumor sections. TRITC-uIONP and FITC-IONP20 were i.v. co-injected in the same mice bearing orthotopic 4T1 mouse mammary tumors. Images were recorded from the tumor collected at $3 \mathrm{~h}$ after coinjection. The extravasation of two different nanoparticles from the same tumor vessel, which is seen as an irregular donut with the brightest fluorescent intensity, can be observed based on two distinct fluorescent colors. 3D rendering of the volume reconstructed from z-stacked images of the selected tumor sections showing the spatial distributions of TRITC-uIONP (B) and FITC-IONP20 (C) in a tumor after extravasating from the vessel (colored in blue), and (D) the corresponding profiles of the amounts of nanoparticles with two different sizes over the distance away from the vessel. (Reprinted with permission from Ref. [86]. Copyright 2017, American Chemical Society)

characterize macrophage classification, ${ }^{100}$ stenosis of atherosclerotic plaques, Au-PEG NPs conjugated with tumor specific antibodies were used to examine the tumor cell distribution by CT imaging in mice models. ${ }^{101}$ Silvestri and colleagues developed a water stable Au NPs functionalized with glucosamine that showed a combined spatial resolution with metabolic information during CT imaging. ${ }^{102}$ Smaller sized PAMAM entrapped AuNPs are more advantageous in getting enhanced CT signals due to their more easily internalization. Besides, porous $\mathrm{Au}$ NPs were shown to exhibit brighter contrast signals than solid ones. ${ }^{103}$ Alloy NPs such as Au-Ag NPs produced strong DEM and CT contrast and accumulated in breast tumors before excreted via urine and feces. ${ }^{104}$ A multifunctional platform of Au NPs capped with aminoPEGs and conjugated with targeting molecule Annexin $\mathrm{V}$ and radionuclide Tc-99m helped to better localize and diagnose vulnerable atherosclerotic plaques. ${ }^{105}$

For MR imaging, positive (T1) and negative (T2) nanosized contrast agents have been developed. In the last decade, superparamagnetic iron oxide NPs (SPIONs) have been the gold standard for MRI cell tracking and even translated into clinical use. Wang et al. have used ultrafine iron oxide NPs (3.5 nm core size) for MR imaging of tumor and they found these NPs can easily extravasate from the tumor vasculature and readily diffuse into the tumor tissues in comparison with larger-sized ones (Fig. 9). ${ }^{106}$ In vivo MR imaging showed these NPs demonstrated bright T1 contrast at $1 \mathrm{~h}$ after IV administration and followed by dark T2 contrast in the tumor after $24 \mathrm{~h}$. Wei et al. studied the effectiveness of $\mathrm{pH}$-responsive SPIONs to enhance the MRI sensitivity and specificity of tumors by targeting acidic tumor microenvironments. ${ }^{107}$ Their findings are quite promising and indicated great potential for early stage diagnosis. However, SPIONs labeled cells produced hypointensities on a T2/T2-weighted MR images, which were hard to be distinguished from other hypointense regions in certain disease models. Alloy NPs comprised of a magnetic core and gold shell exhibited concentration-dependent contrast in MR imaging. The transmigration study of these NPs using a blood-brain barrier model proved enhanced transmigration efficiency and showed potential for imaging in brain or neurological disorders. ${ }^{108}$ Sun et al. have used iron oxide NPs coated with polymer and labeled with fluorine-18 for PET/MR dual modality imaging which reduced procedure time and radiation exposure. ${ }^{109} \mathrm{Xu}$ and coworkers synthesized a trimodal imaging agent composed of gold cluster and gadolinium oxide integrated NPs which demonstrated strong X-ray absorption for CT imaging, a high $\mathrm{rl}$ value for MR imaging and a red fluorescence at $660 \mathrm{~nm}$ emission for optical imaging. ${ }^{110}$

Gd complex based contrast agents were developed as good alternative MRI contrasts to generate the positive contrast (hyperintensity). However, they usually suffer from short residence time and 
A

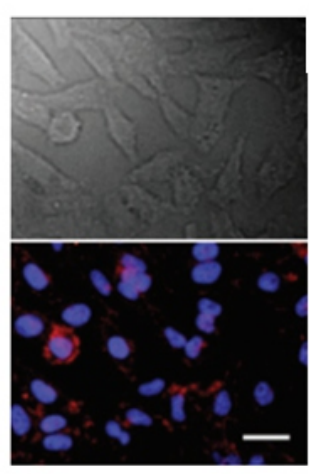

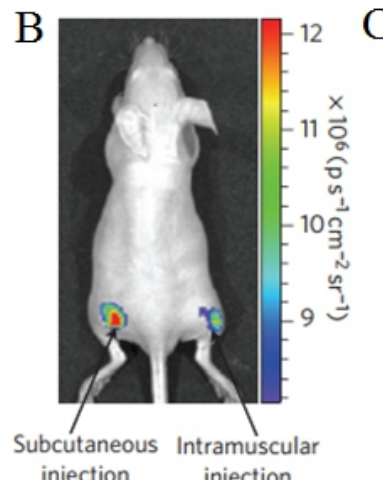

injection
C

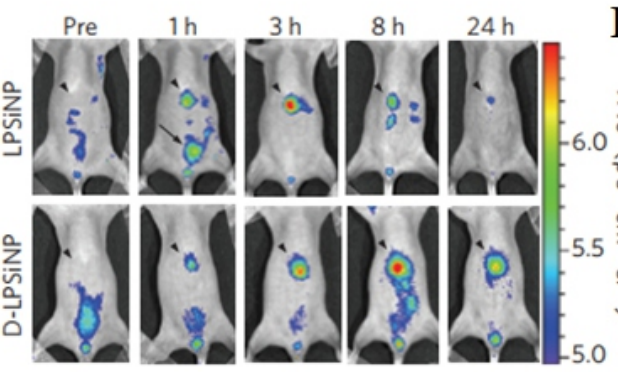

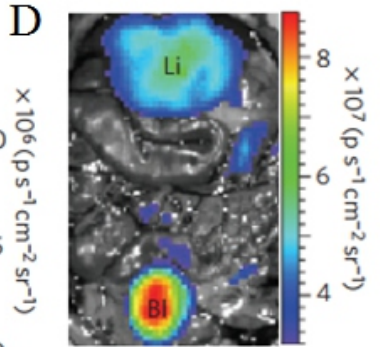

F

Li Sp $\quad$ K LN $\quad$ H $\quad$ BI Lu Sk $\quad B r$
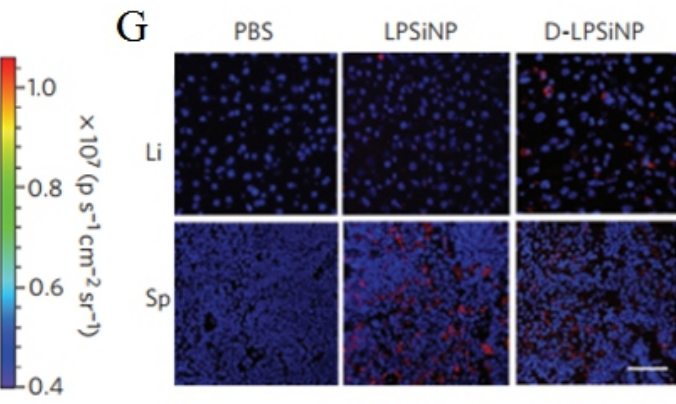

Fig. 10 In vitro, in vivo and ex vivo fluorescence imaging with LPSiNPs. A, In vitro cellular imaging with LPSiNPs. HeLa cells were treated with LPSiNPs for $2 \mathrm{~h}$ and then imaged. Red and blue indicate LPSiNPs and cell nuclei, respectively. The scale bar is $20 \mu \mathrm{m}$. B, In vivo fluorescence image of LPSiNPs (20 $\mu \mathrm{l}$ of 0:1 $\mathrm{mg} \cdot \mathrm{ml}-1)$ injected subcutaneously and intramuscularly on each flank of a mouse. C, In vivo images of LPSiNPs and D-LPSiNPs. The mice were imaged at multiple time points after intravenous injection of LPSiNPs and D-LPSiNPs (20 mg.kg-1). Arrowheads and arrows with solid lines indicate liver and bladder, respectively. D, In vivo image showing the clearance of a portion of the injected dose of LPSiNPs into the bladder, $1 \mathrm{~h}$ post-injection. Li and $\mathrm{Bl}$ indicate liver and bladder, respectively. E, Lateral image of the same mice shown inC, $8 \mathrm{~h}$ after LPSiNP or D-LPSiNP injection. Arrows with dashed lines indicate spleen. F, Fluorescence images showing the ex vivo biodistribution of LPSiNPs and D-LPSiNPs in a mouse. Organs were collected from the animals shown in C, 24 h after injection. Li, Sp, K, LN, H, Bl, Lu, Sk and Br indicate liver, spleen, kidney, lymph nodes, heart, bladder, lung, skin and brain, respectively. G, Fluorescence histology images of livers and spleens from the mice shown in $\mathrm{C}$ andF, $24 \mathrm{~h}$ after injection. Red and blue indicate (D-)LPSiNPs and cell nuclei, respectively. The scale bar is $50 \mu \mathrm{m}$ for all images. (Reprinted with permission from Ref. [94]. Copyright 2009, Nature Publishing Group.)

weaker cell permeability. Some of Gd based nanoparticulate contrast agents have been developed to overcome these shortcomings of the complex agents. ${ }^{111} \mathrm{MnO}$ NPs has been explored as a new T1 MRI contrast agent. They were used for cell labeling and in vivo MRI tracking though showing a short duration of and weak signals which needs further improvements. ${ }^{12}$

Furthermore, in contrast to most optically active nanomaterials, luminescent porous silicon (LPSi) NPs self-destruct and are excreted in a mouse model without evidence of toxicity. ${ }^{113}$ They were shown to accumulate mainly in MPS-related organs and were degraded into nontoxic products within a few days. Dextran-coated LPSiNPs were successfully applied for tumor imaging in a live mouse model by showing a passive accumulation as revealed in near-IR fluorescence imaging $^{114}$ (Fig. 10). Mesoporous silica NPs are also used as promising ultrahigh field MRI imaging contrast agents. ${ }^{15-118}$

Carbon nanomaterials (CNMs) have also shown great potential in clinical imaging applications. They are ideal platforms for the attachment of NPs. NP/ CNM hybrids not only combined the unique properties of the NPs and CNMs but also display new characteristics resulted from interactions between the two entities. $\mathrm{C}_{60}$ buckyballs and cylindrical single-walled or multi-walled carbon nanotubes can readily accommodate the payload of diagnostic and/or therapeutic agents.
Various efforts have been devoted to solubilize them in water via different surface modifications towards diagnostic and/or therapeutic applications. For example, magnetic iron oxide NPs/ CNM hybrids were demonstrated to enhance the cancer cell detection during MRI imaging, giving rise to strong MRI contrast both in vitro and in vivo. ${ }^{119}$ $\mathrm{Xu}$ et al. reported graphene oxide-iron oxide NPs for efficient tumor targeting and multimodality imaging. ${ }^{120}$ Chaudhary et al. demonstrated that Fe core-carbon shell NPs enhanced MRI contrast signals. ${ }^{121}$ Metelkina and coworkers engineered hybrid magnetite-carbon nanofiber materials for MRI imaging contrast agents. ${ }^{122}$

Synthetic polymeric NPs are used in clinical imaging as well. For example, Zhang et al. reported a multifunctional NPs composed of a NIR-emiting polymer semiconductor core, oligo (ethyleneglycol) and folic acid shell to produce water solubility and cell recognition. The polymer semiconductors exhibited narrow emission spanning NIR spectrum, indicating the ability to specifically target and label folate receptor positive cancer cells. ${ }^{123} \mathrm{Hu}$ et al. reported perylene diimidegrafted polymeric NPs for dual-modal photoacoustic and MRI imagingguided photothermal therapy. ${ }^{124}$ Yildiz et al. used doxorubicin-loaded NIR fluorescent polymeric NPs for concurrent imaging and therapy of mammary adenocarcinoma. ${ }^{125}$ 


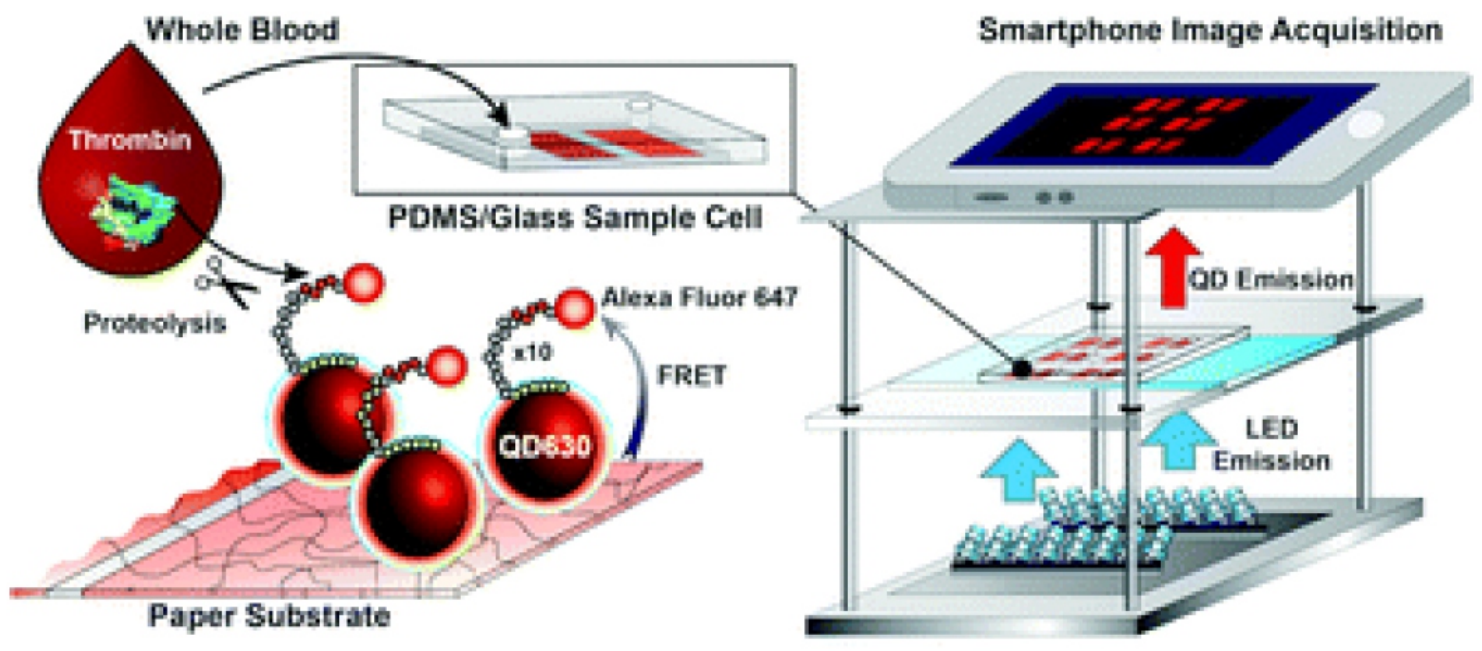

Fig. 11 Schematic representation of a semiconduct quantum dot-ased assay format for single step, FRET based detection of thrombin hydrolase activity in serum and whole blood. Reprinted with permission from Ref. [136]. Copyright, 2015, Royal Society of Chemistry.)

\subsection{Applications of NPs in biosensing, diagnosis, theranostic, drug delivery and/or concurrent therapy}

Many kinds of NPs have been developed for constructing biosensors, diagnostic/theranostic units and drug delivery and/or therapy carriers. As a rapidly developing branch of nanotechnology, Cancer nanotechnology is mainly concerned with the application of both nanomaterials (such as NPs for tumor imaging or drug delivery) and nanotechnology approaches (such as NP-based theranostics). The latest progress in this field as well as applications of NPs for other disorders are briefly reviewed as follows.

\subsubsection{NPs based biosensors, diagnostic or theranostic units}

$\mathrm{Au}$ NPs (GNPs) are frequently used in biosensing, due to their unique optical properties and ease of use with different biomarkers. ${ }^{126,}{ }^{127}$ Depending on their size and shape, the optical properties such as optical absorption and scattering peaks can be varied towards the NIR optical window for better in vivo applications. Besides, the light-scattering properties and large enhancement ability of local electromagnetic field make it possible for GNPs to be used as signal amplification tags in biosensing. ${ }^{128}$ Moreover, they are capable of transferring electrons efficiently and based on these features, DNA sensors built with GNPs were found to be 1000 times sensitive than those without GNPs. ${ }^{129}$ GNPs conjugated with DNA will produce additional plasmonic band upon hybridization with a complement sequence, and reached a sensitivity that as low as 200 pM DNA can be detected. ${ }^{130}$ GNP based glucose biosensors have a detection limit of $0.18 \mathrm{uM},{ }^{131}$ while a NADH sensor based on GNPs shows $780 \mathrm{mV}$ potential decreases without any electron transfer mediators. ${ }^{132}$ Ag NPs were also very useful as novel biosensors due to their catalytic properties. In 2008, a $\mathrm{H}_{2} \mathrm{O}_{2}$ biosensor based on direct electrochemistry of $\mathrm{Hb}$ in $\mathrm{Hb}-\mathrm{Ag}$ sol on a glassy carbon electrode. ${ }^{133}$ In 2009, Liu and $\mathrm{Hu}$ developed a novel $\mathrm{H}_{2} \mathrm{O}_{2}$ biosensor based on electrocatalysis of myoglobin immobilized on Ag NPs doped carbon nanotube film. ${ }^{134}$ Magnetic NPs (MNPs) are also being used to detect a variety of biomolecules (nucleic acids, enzymes, proteins, drugs or tumor cells) with excellent sensitivity. They have been successfully applied in diagnostic magnetic resonance (DMR). In 2012, Claussen et al. reported the design of a hybrid biosensor with glucose oxidase immobilized on a 3D matrix made of multilayered graphene petal nanosheets and Pt NPs, which exhibited great glucose detection sensitivity. ${ }^{135}$

FRET is a non-radiative energy transfer process between higher energy donor and lower energy acceptor. QDs based FRET bioassays and bioprobes, the first generation of QDs based bioassays, were developed on the basis of the strong distance dependence of FRET. Depending on the specific case or availability of other excellent donors, QDS can be both used as acceptors instead of as donors only. A few new types of NPs-based QDs biosensor are worthy of mentioning. For instance, Petryayeva et al. recently demonstrated a QDs-based assay format for the one step, FRET-based detection of thrombin hydrolase activity in serum and whole blood (Fig. 11). ${ }^{136} \mathrm{CdSe} / \mathrm{CdS} / \mathrm{ZnS}$ QDs with peak emission at $630 \mathrm{~nm}$ were conjugated with Alexa fluor 647 labeled peptide for thrombin activity and immobilized on paper test strips inside the sample cells. Quantitative results were obtained in less than 30 min with a limit of detection $18 \mathrm{NIH}$ units $\mathrm{mL}^{-1}$ of activity in $12 \mu \mathrm{L}$ of whole blood (Fig. 12). ${ }^{136}$ Another example of this is a UCNP (up conversion NPs)-CdTe QDs probe which is capable of detecting mercury ions in human serum with great sensitivity and selectivity (Fig. 13). ${ }^{137}$ UCNPs are a new class of fluorophores. The absorber ion (energy donor) is excited by NIR light (usually $980 \mathrm{~nm}$ diode laser), and transfer the energy to the emitter ion (energy acceptor) which emits narrow emission band in the visible-NIR range. In contrast with FRET, chemiluminescence and bioluminescence resonance energy transfer (CRET and BRET) generated energy donor through chemical reaction and thus avoiding the difficulties of using QDs as energy acceptor. A novel example of this was a QD modified aptamer probe for CRET, which used capillary electrophoresis based on CRET from HRP (horseradish peroxidase) and QDs in the presence of CEA. ${ }^{138}$ 

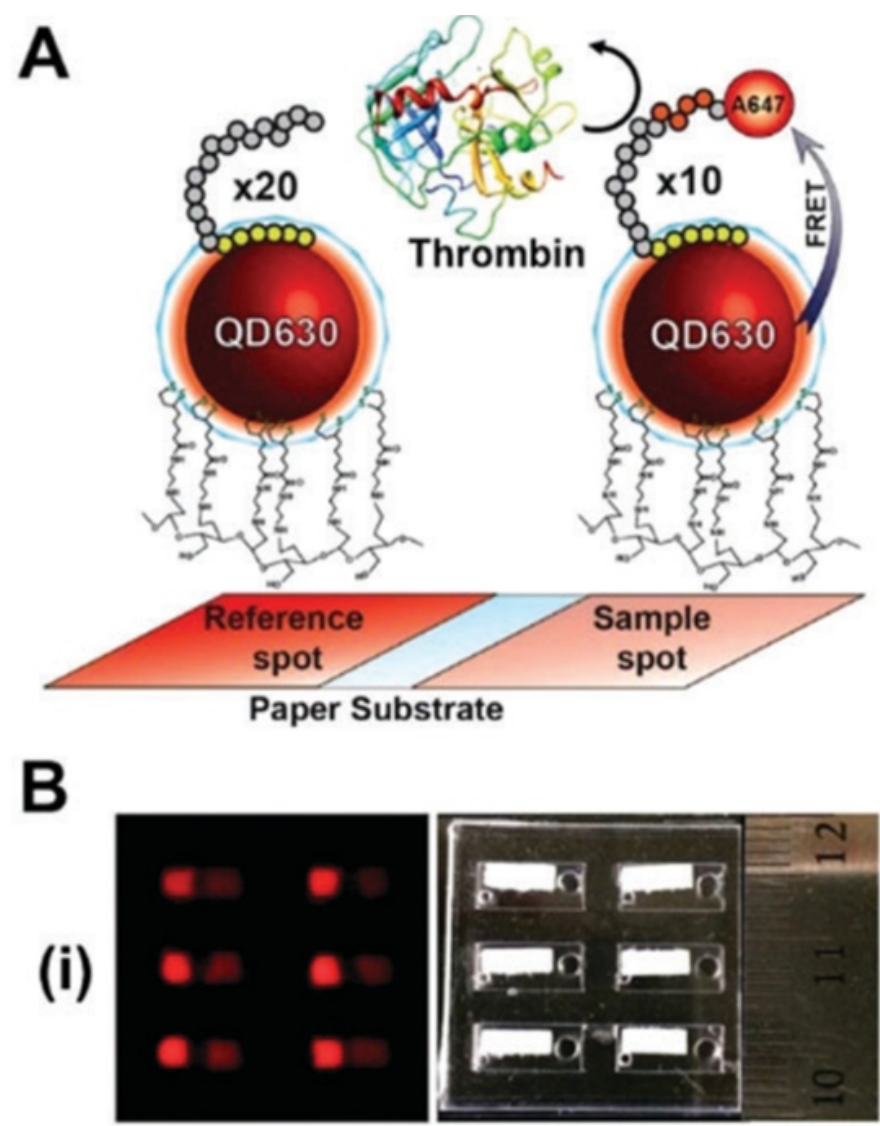

\section{LED illuminated White light}

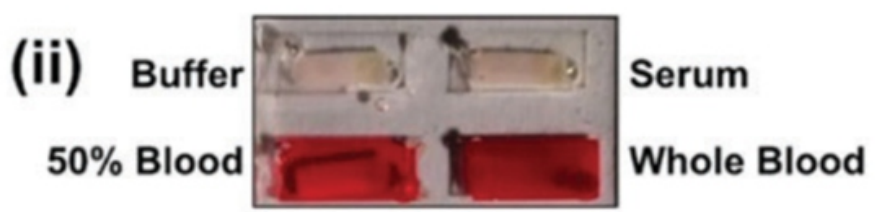

Fig. 12 (A) Design of paper test strips to measure thrombin activity via FRET with immobilized QD donors and A647 acceptor dye-labeled peptide substrates containing a cleavage site recognized by thrombin. Protease activity was measured through the recovery QD PL with loss of FRET. (B) Paper test strips with sample and reference spots of immobilized QD peptide conjugates were (i) enclosed within PDMS/glass sample cells that were then (ii) filled with a biological sample matrix such as serum, diluted blood or whole blood. Note the opacity of the whole blood. (Reprinted with permission from Ref. [136]. Copyright 2015, The Royal Society of Chemistry.)

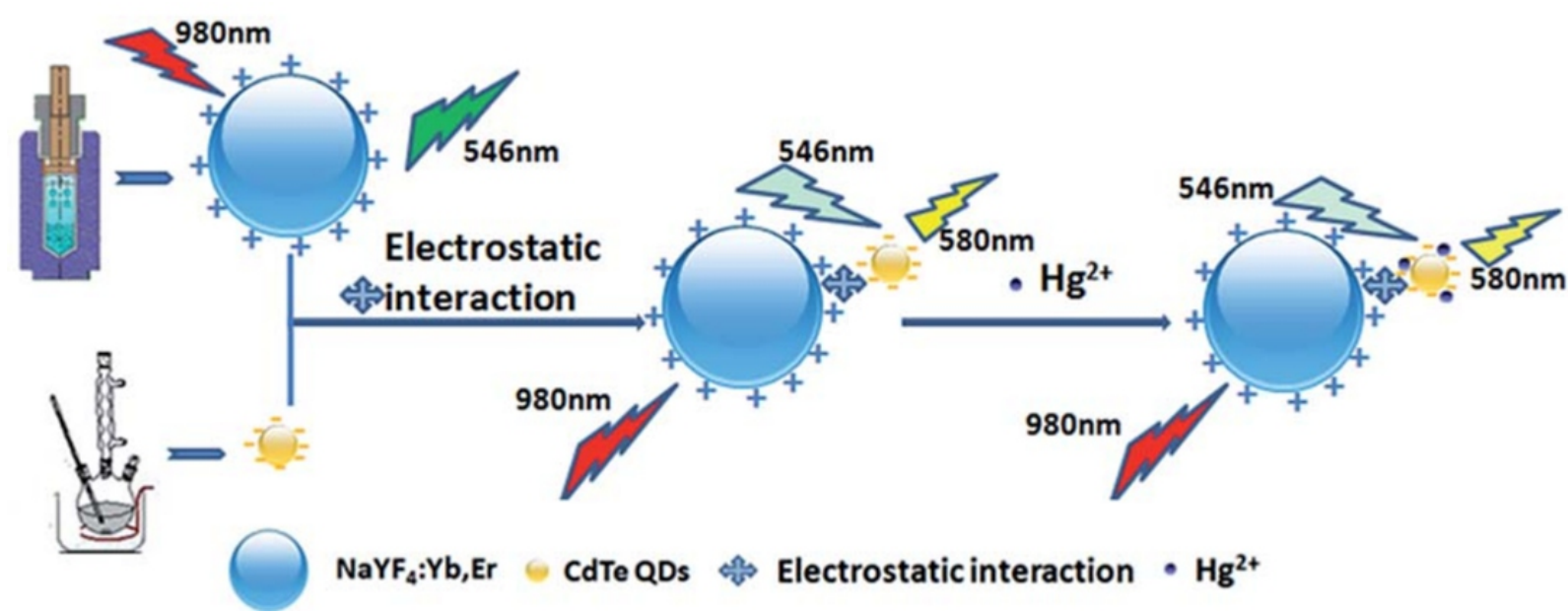

Fig. 13 Principle of upconversion mercury ions FRET detection by employing UCNPs as donor and QDs as acceptor. (Reprinted from Ref. [137] with permission from The Royal Society of Chemistry.) 


\subsubsection{NPs-based drug delivery and/or concurrent therapy systems}

A large majority of research in nanomedicine is focused on the application of NPs in drug delivery or therapy or both. An ideal drug delivery system should meet the following criteria: specific drug targeting and delivery without off-target effects and without eliciting cellular or noncellular resistance, without discomposing the drug, maintaining biocompatibility during application and therapeutic processes, and faster production. The success of an efficient drug delivery system depends on the release, diffusion and biodegradation of delivered drugs. Drug delivery systems are used to alter the pharmacokinetics (PK) and biodistribution (BD) of the loaded drugs or may simply function as drug reservoirs. To date, as discussed below, various classes of NPs based nanoplatforms have been designed and evaluated as efficient drug delivery and/or concurrent therapy systems in the treatment of cancer and many other disorders.

Biodegradable and biocompatible synthetic polymers such as poly (lactic acid) (PLA), poly (lactide-co-glycolide) PLGA, poly (L-lysine), poly (glutamic acid), poly (malic acid) and so on have been extensively used to fabricate nanospheres for the delivery and controlled release of hydrophobic drugs to target sites. Smart polymer NPs can be produced by coating these polymers with other polymers such as PEG, poloxamers, polysaccharides, which released their payload upon stimulated by $\mathrm{pH}$, temperature, light, or ionic strength. ${ }^{139}$ Sun et al. recently reported a polymer NPs based on a narrow band gap D-A conjugated polymer, which showed excellent potential for near infrared photoacoustic imaging and photothermal therapy. ${ }^{100}$ Chauhan et al. reported enhanced EPR directed and imaging-guided photothermal therapy by a novel hybrid nanomaterial Toco-Photoxil developed by Vitamin E modified gold coated PLGA NPs with PgP inhibitor incorporated. ${ }^{141}$

Recently, CDs have attracted great attention owing to their superior properties, such as fluorescence, high quantum yield, uniform distribution and biocompatibility. Those properties make CDs also interesting for therapeutic delivery, optogenetics, and theranostics. For instance, Kim et al. demonstrated the power of gene silencing and bioimaging in vitro and in vivo by fluorescent Carbon Dots NPs conjugated with siRNA. ${ }^{142}$ Li et al. used transferrin conjugated CDs for targeted delivery of doxorubicin to brain tumor cells. ${ }^{143}$ Guo et al. reported the development of a new class of near-IR light induced CDs, $\mathrm{Cu}$, N-doped CDs, which markedly inhibited cancer via synergistic photothermal/photodynamic therapies. ${ }^{144}$ Lan et al. prepared S, Secodoped CDs allowed NIR emissions and photothermal conversion of the CDs through the two-photo excitation mechanism. ${ }^{145}$ For more details on CDs-mediated therapy, you can refer to a recent review paper. ${ }^{146}$

UCNPs, a new generation of phosphorescence, has recently attracted significant research interest. Owing to its suitable size distribution and biocompatibility, UCNPs could be conjugated with various kinds of biomolecules, resulting in the development of numerous biodetection assays and therapeutic modalities. For example, Yang et al. reported effective NIR light-induced siRNA delivery in vitro and in vivo using siRNA loaded silica coated UCNPs (Si-UCNPs). ${ }^{147}$ Zhao et al. introduced multifunctional core-shell UCNPs [UCNP@SiO(2) $(\mathrm{AlC}(4) \mathrm{Pc})$ nanoparticles] for imaging and photodynamic therapy of liver cancer cells. ${ }^{148}$ Lim et al. found that photosensitizers conjugated UCNPs effectively reduced the infectious virus titers in vitro with no clear pathogenicity in murine model and increased target specificity to virus-infected cells. ${ }^{149}$ Cui et al. developed UCNPs coated with folatemodified amphiphilic chitosan (FASOC) to anchor ZnPC photosensitizer and confocal microscopy and NIR small animal imaging demonstrated enhanced tumor-selectivity of the nanoconstructs to cancer cells, higher ROS generation in them, and up to $50 \%$ tumor inhibition ratio by in vivo NIR light-triggered PDT. ${ }^{150}$ Due to limited spaces, application of UCNPs in drug delivery and/or therapy will not be discussed any further, there are a few notable review articles about the recent progress in this field ${ }^{151-153}$.

Liposomes, as the first generation of nanosized drug deliverers, has been developed and successfully used for packaging of chemotherapeutics. It is considered as one of the most successful drug delivery systems and a few of them have been approved by US FDA for clinical disease treatment. One major concern for this type of drug delivery system is the solubility of drugs as we know that hydrophilic drugs are easily entrapped with a high degree of latency while hydrophobic ones can be rapidly released. To overcome those issues, some remote loading techniques via $\mathrm{pH}$ or chemical gradients have been developed to increase the drug accumulation and retention. For instance, back in 1998 Doxil was the first FDA approved liposomal drug formulation for AIDS-associated with Kaposi's sarcoma. ${ }^{154}$ Other liposomal drugs used in clinical treatment include Ambisome, DaunoXome, DepoCyt, Visudyne and etc.

The presence of blood-brain-barrier (BBB) posed a significant challenge for delivering drugs to the CNS systems. Polymeric NPs seem to be a promising solution to these problems. Kreuter et al. first reported the use of the poly(butylcyanoacrylate) NPs to deliver dalargin to the CNS in $1995 .{ }^{155}$ In 2006, Koziara et al. reported the use of paclitaxel encapsulated cityl alcohol/polysorbate NPs. ${ }^{156}$ Later on, Liu and coworkers reported that PLA NPs loaded with breviscapine was able to penetrate $\mathrm{BBB}^{157}$ and Geldenhuys et al. also demonstrated that paclitaxel loaded PLGA NPs improved BBB bypass. ${ }^{158}$ Other than those, $\mathrm{MnO}$ NPs are also found to translocate to the brain via olfactory route. ${ }^{159}$

Engineered NPs were improved with enhanced specificity by targeting specific receptors on the cancer cells by conjugating with the complementary ligands. A variety of important receptors were targeted for these purposes, which include FA receptors, transferrin receptors, asialoglycoprotein and so on. For instance, Liang et al. formulated FAfunctionalized LDL-carboxymethyl cellulose (CMC) NPs for tumor targeting and results indicated great potential for this kind of new $\mathrm{pH}-$ responsive and FA-tagged nanocarriers as an efficient drug delivery system in cancer therapy ${ }^{160}$ In another study, a targeted drug delivery system was reported by employing silica NPs loaded with an EGFR inhibitor, Cetuximab and anti-cancer drug Dox. ${ }^{161}$ The results demonstrated superior tumor homing and anticancer efficiency in contrast to control NPs with only one drug loaded, this is probably due to EGFR medicated endocytosis and combined therapeutic effects of $\mathrm{CET}$ and Dox. A GO-based nanoplatform with $\mathrm{mAb}$ against folliclestimulating hormone receptor (FSHR) was shown to be a useful tool in detecting early metastasis and delivering therapeutics. ${ }^{162}$ Moreover, Suo et al. recently reported $\mathrm{PgP}$ antibody conjugated carbon nanotubes which induced targeted photothermal therapy against tumor spheroids of MDR cancer cells. ${ }^{163}$ Hyaluronic acid (HA), the natural linear polysaccharide, is able to bind CD44 receptors and internalize into tumor cells, indicating promising potential for targeting CD44 positive tumors. For example, Sargazi et al. employed PEG-HA NPs for MTX (mitoxantrone) delivery and it inhibited CD44 receptor positive MDAMB-231 cells. ${ }^{164}$

Drug resistance by the cancer cells poses significant challenges in the treatment of cancer. Novel approaches for overcoming drug resistance are urgently needed. A noninvasive approach, photothermal therapy (PTT) is actively pursued and starts to show great promise in 
combating this problem. A variety of NPs such as graphene, ${ }^{165,166}$ carbon nanomaterials, ${ }^{167,}{ }^{168}$ gold nanostructures, ${ }^{169,170}$ palladium $^{171,172}$ or copper $^{173,174}$ based NPs are being extensively investigated as NIRassisted PTT agents. However, NPs-mediated PTT is hard to induce complete tumor eradication due to non-uniform distribution of hyperthermia. To overcome this issue, there are more and more studies on developing multifunctional alloy nanoplatforms which combines traditional chemotherapy with photothermal therapy (PTT). For instance, Zhang et al. recently reported a type of copper $(\mathrm{Cu})$-palladium (Pd) alloy tetrapod NPs which exhibited superior NIR photothermal conversion efficiency and induced pro-survival autophagy that is exploited by autophagy inhibitor such as 3-methyl adenine or chloroquine to enhance cancer killing in triple-negative breast cancer models. Pedrosa and et al. applied combination of chemotherapy and Au NPs photothermal therapy to tackle doxorubicin resistance in cancer cells. ${ }^{175}$ Cao et al. reviewed in details the recent progress in synergistic chemotherapy and phototherapy by various types of NPs for cancer treatment. $^{176}$

Other than applications in cancer treatment, NPs also offer efficient therapy in many other disorders such as neurodegenerative, inflammatory diseases. Liposomes have long been used as a carrier for the antifungal drug amphotericine $\mathrm{B}$ to treat systemic fungal infection. ${ }^{177}$ Associating heparin with polymethacrylate NPs significantly improved the anti-inflammatory efficiency of the drug in an ulcerative colitis model. ${ }^{178}$ Bone cement functionalized with mesoporous silica NPs with antibiotics loaded gave out extended release of gentamicin. ${ }^{179}$ Chitosan based multifunctional nanocarriers modified by L-valine and phenylboronic acid have been designed to overcome multiple barriers for oral delivery of insulin and these insulin-carried NPs exhibited effective hypoglycemic effects. ${ }^{180}$ Functionalized SWCNT was suggested as a novel approach to AD's therapy. ${ }^{181}$ Saraiva et al. used miR-124 loaded NPs in a PD disease model, 6-OHDA lesioned mice, and they showed increased number of new neurons in the olfactory hub and enhanced migration of new neurons into striatum. ${ }^{182}$ McMaster et al. used a hollow NPs to deliver peptide therapeutics into osteoarthritis. ${ }^{183}$ Drug loaded hollow NPs delivered active dose of drugs to bovine cartilage explants, suppressed pro-inflammatory IL-6 expression after IL- $1 \beta$ stimulation.

Meanwhile, there is a growing interest on NPs-based therapy for infectious diseases caused by pathogenic bacteria, especially for combating the increasingly severe multidrug resistance problems. For example, Huang et al. showed that combination of chitosan and silver NPs exerted synergistic antimicrobial efficacy against Gram-positive MRSA and Gram-negative P.aeruginosa strains. ${ }^{184}$ Ding et al. reported the size-dependent bacteria-killing effects of different sized Ag NPsbased nanocarriers conjugated with antibiotics and indicated another way of combating the worsen multidrug resistance problems. ${ }^{185}$ Makarovsky et al. also reported strong antibacterial activity by sliver NPs complexed with bovine submaxillary mucin. ${ }^{186}$ Kim et al. reported that siRNA conjugated silica NPs are effective in modulating macrophage immune responses to S. aureus infections. ${ }^{187}$ Yang et al. reported a unique intracellular antibiotic delivery NP which consists of mesoporous silica NPs loaded with gentamicin and bacterial toxin responsive lipid bilayer surface shell, and a bacterial targeting peptide, which demonstrated rapid drug release and effective inhibition of $\mathrm{S}$. aureus in vitro and in vivo. ${ }^{188}$ Yuan et al. reviewed the recent efforts on developing various meta or metal oxide-based NPs for bacterial detection and infection therapy. ${ }^{189} \mathrm{Zhu}$, Colino and their coworkers discussed the progress of nanoplatforms based on various types of NPs in the control of microbial infection from diagnosis to therapy. ${ }^{190,} 191$
Recent advance in drug delivery of NPs has made some progress on enhancing their biosafety via protection of genetic materials until delivery to therapeutic target. ${ }^{192}$

\section{Potential risks: Toxicity of NPs}

Although NPs have been developed for various kinds of biomedical applications, a large majority of them are halted at in vitro study stages due to unforeseeable risks associated with production or exposure of NPs to our biological system. NPs usually possess some unique properties such as small size, large surface area, completely different physical or chemical features from their bulk counterparts and because of that, it may trigger unwanted cytotoxicity or genotoxicity. ${ }^{193}$

Numerous studies are in progress to address those important issues. For instance, $\mathrm{Xu}$ group researchers investigated the toxicity of $\mathrm{Ag} / \mathrm{Au}$ NPs on the development of transparent zebrafish embryos, and results showed the composition, size of NPs all affected the cytotoxicity of NPs on the development of zebrafish embryos as manifested by various types of deformation of embryos. ${ }^{194-197}$ Other popular cytotoxicity and inflammatory response assays have been used to detect toxicity of NPs such as MTT, Calcein AM, Protease activity assays, macrophage function assays and so on. Those in vitro assays have been applied to assess the cytotoxicity and immune response of a variety of cells to various types of NPs and results were quite divergent. For instance, Chen et al. reported aluminum oxide NPs decreased expression of tight junction proteins in brain vasculature ${ }^{198}$. Radzium et al. also evaluated the cytotoxicity of aluminium oxide NPs on mammalian cells and did not find any cytotoxicity at tested range of concentrations. ${ }^{199}$ Connor et al. reported Au NPs did not cause acute cytotoxicity as well. ${ }^{200}$ Aruoja et al. demonstrated the toxicity of $\mathrm{CuO}, \mathrm{ZnO}$ and $\mathrm{TiO}_{2} \mathrm{NPs}$ to alga growth. ${ }^{201}$ Naqvi et al. reported concentration-dependent toxicity of iron oxide NPs medicated by elevated ROS levels in tested cells. ${ }^{202}$ Magrez et al. evaluated cellular toxicity of carbon-based nanomaterials and results also indicated size dependent cytoxicity. ${ }^{203}$ Dhawan et al. showed colloidal C60 fullerenes elicited considerable genotoxicity. ${ }^{204}$ Park et al. demonstrated oxidative stress and pro-inflammatory responses induced by silica NPs in vitro and in vivo. ${ }^{205}$ Increased levels of ROS, TNF- $\alpha$, IL-1 $\beta$, IL-6, iNOS were found in NPs exposed RAW264.7 cells or macrophages harvested from silica NPs treated mice. ${ }^{205}$ Grabowski et al. analyzed the toxicity of polymeric PLGA NPs on THP-1 macrophages and results showed that at high concentrations $(>1 \mathrm{mg} / \mathrm{ml})$, cytotoxicity was found to be induced by the presence of stabilizers. ${ }^{206}$ However, stabilizer-free PLGA NPs exerted no cytotoxicity. Sayes et al. compared the toxicity of different types of NPs by in vitro measurements to in vivo pulmonary toxicity profiles and find little relevance between them. ${ }^{207}$ For more details on the study of NPs toxicity, please read a review paper by Bahada et al. $^{208}$

Though numerous reports evaluated the potential risks of NPs to biological system, their results are hardly inconsistent, which made it hard for us to refer to any of them for further applications. Toxicity studies for those popular NPs such as iron oxide, gold or silica NPs still can't reach a consensus opinion in terms of their potential risks. This is largely due to lack of standard protocols for the assessment of NPs' toxicity and also it is an indication of the complexity of this issue we are confronted. ${ }^{209,}{ }^{210}$ The cytotoxicity of NPs is affected by many parameters such as cell lines, culture conditions, way of introducing NPs into in vivo systems, size, concentration, exposure time of NPs and etc. $^{211,212}$ Unfortunately, there is also no standard protocols available at the current stages. The cell line to test in vitro is critical in evaluating the degree of cytotoxicity of NPs as it could be varied depending on their preparation methods. Besides, test methods on the same NPs may 
give different results. NPs that usually absorb or emit light may interfere with those assays relying on staining dyes. For example, Monteiro et al. studied the cytotoxicity of a variety of carbon nanomaterials such as single-walled carbon nanotubes (SWCNT), C60 fullerenes, carbon black (CB), $\mathrm{nC}(60)$, and QDs using various in vitro toxicity assays ${ }^{213}$. The results of dye-based assays varied a great deal, depending on the interactions of carbon nanomaterials with the dyes and thus classical toxicology assays may not be suitable for evaluating NPs toxicity. Surface chemistry of NPs may be another factor that may contribute to the caused cytotoxicity. As introduced above, Grabowski and colleagues found the presence of stabilizer on the NPs could make a big difference in their potential cytotoxicity. ${ }^{206}$ Yang et al. also indicated that particle surface features play an important role in phototoxicity of alumina NPs. ${ }^{214}$ Clift et al. studied the uptake, kinetics and cellular distribution of different surface coated QDs in murine macrophage cells and results also implied the significant role of surface coating on the mode of NPs interaction with cells. ${ }^{215}$ However, Cecilia's recent study did not find significant difference in terms of cytotoxicity exerted by different surface capped Au NPs. ${ }^{216}$ Kim et al. reviewed in detail the role of surface functionality in assessing NP cytotoxicity. ${ }^{217}$

Other studies argue that particle size is a more important determinant than their surface chemical properties. For example, Cho et al. assessed the impact of size of silica NPs on their tissue distribution and elimination and results showed that small sized silica NPs can be readily cleared to urine and bile than their larger sized counterparts. However, larger NPs exerted increased inflammatory response within $12 \mathrm{~h}$ of single dose of NPs injection. ${ }^{218}$ Shang et al. reviewed the impact of size on the interactions of engineered NPs with cells and confirmed that NP size affects cytotoxicity upon internalization. In general, smaller NPs posed greater toxicity than their larger sized counterparts because they can be readily taken into cell or subcellular organelles while large ones are more likely to be eradicated by the biosystem.

In addition, there are a few things we should bear in mind when predicting possible toxicity of NPs. First, the microenvironment NPs are faced in in vivo system is much complicated than the in vitro test. So any conclusions reached from in vitro assays can not be just extrapolated as same or similar in in vivo studies and in vivo studies in animal models is the least that should be done when assessing their internal risks. Second, the currently available assays all suffer from intrinsic drawbacks and thus further endeavors are required to advance technologies for better assaying NPs' toxicity. The dawn of cutting-edge single-cell assay techniques may provide a promising alternative for assessing cytotoxic and immune responses to NPs in a multiplexed manner. These assays will find greater applications in safety studies of various types of NPs. Single cell analysis will also work together with conventional bulk assay to investigate the safety of NPs in highthroughput at single-cell level.

Therefore, before we can fully access any potential risks that NPs may bring to the biological system and apply them into biomedical applications afterward, we must be aware how our system is going to react to exposed NPs, what is the fate of NPs presented to cells and the internal effects of NPs exerted at the molecular and cellular levels. In short, toxicity assessment studies are largely short and still at their early stages. Experimental conditions, protocols, preparation of NPs all together affect the toxicity results they may cause. More extensive investigations are warranted before pushing for any further researches.

\section{Conclusion}

The cutting-edge nanotechnology starts to show great impact in the biomedical sciences in the past decade. Due to their unique physical and chemical properties, in recent years, we have witnessed the modern applications of NPs, such as QDS, Au/Ag NPs, magnetic iron oxide NPs, carbon dots, synthetic polymeric NPs and upconversion NPs in biomedical fields for optical/fluorescent imaging (Table 1), biosensing, targeted drug delivery and/or concurrent therapy. They are actively engaged in CR, MRI, and clinical imaging as superior alternative contrast agents, and NPs-mediated dual or multi-mode imaging techniques are being developed for the diagnosis of various diseases.

Other important applications of these NPs in the biomedical field are the targeted drug delivery and/or concurrent therapy. Various kinds of drug molecules could be incorporated into NPS-based drug nanocarrier system. So far, various classes of multifunctional NPs (bare or surface modified, made of single chemical compound or alloy polymers, with single- or multiplexed functionalization with drug, target tag, immune response activator or as all in-one smart nanoplatform) have been developed for targeted delivery of drugs to local sites. Controllable, and inducible drug release to desired (disease microenvironment)-targeted sites start to better control this process.

However, in terms of NPs' toxicities, we need to bear in mind that there has not been sufficient and comprehensive data on the long-term toxicity study of NPs. Judging from the inadequate researches in this regard, there is still a long way to go before we can resolve these issues. We are still short of critical information on biodistribution and release kinetics of NPs in bio-system. Collaborative, multidisciplinary research efforts are in need for successful applications of these NPs in the field of biomedical science.

\section{Conflict of Interest}

All authors approved this manuscript and we declare that there is no competing interest regarding the publication of this manuscript.

\section{Acknowledgement}

This work was partially supported by Wenzhou Medical University Start-up fund (QTJ 18011); National Natural Science Foundation of China (Grant No. 81760513); Guangxi Natural Science Foundation of China (Grant No. 2017JJA10351); Basic Ability Promotion Project for Young and Middle-Aged College Teachers in Guangxi Zhuang Autonomous Region (Grant No. 2017KY0520); Scientific Research Project of Youjiang Medical University for Nationalities (Grant No. yy2016bsky02); Scientific Research Open Project of Key Laboratory in Guangxi's Universities (Grant No. kfkt2017005).

\section{Reference}

1. S. K. Sahoo, S. Parveen and J. J. Panda, Nanomedicine, 2007, 3, 20-31.

2. G. Binnig, C. F. Quate and C. Gerber, Phys. Rev. Lett., 1986, 56, 930-933.

3. G. Binnig, H. Rohrer, C. Gerber and E. Weibel, Phys. Rev. Lett., 1982, 49, $57-$ 61.

4. S. Iijima, Nature, 1991, 354, 56.

5. H. W. Kroto, J. R. Heath, S. C. O'Brien, R. F. Curl and R. E. Smalley, Nature, 1985, 318, 162.

6. C. M. Shea, J. Eng. Technol. Manage., 2005, 22, 185-200.

7. E. Abbasi, T. Kafshdooz, M. Bakhtiary, N. Nikzamir, M. Nikzamir, M. Mohammadian and A. Akbarzadeh, Artif Cell. Blood. Sub., 2016, 44, 885891.

8. C. T. Matea, T. Mocan, F. Tabaran, T. Pop, O. Mosteanu, C. Puia, C. Iancu and L. Mocan, Int. J. Nanomed., 2017, 12, 5421-5431.

9. P. Namdari, B. Negahdari and A. Eatemadi, Biomed. Pharmacother, 2017, 87, 209-222.

10. R. Popovtzer, A. Agrawal, N. A. Kotov, A. Popovtzer, J. Balter, T. E. Carey and R. Kopelman, Nano Lett, 2008, 8, 4593-4596.

11. L. E. Cole, R. D. Ross, J. M. Tilley, T. Vargo-Gogola and R. K. Roeder, Nanomedicine. (Lond), 2015, 10, 321-341. 
Table 1. Summary of applications of NPs in bio- or clinical imaging.

\begin{tabular}{|c|c|c|c|c|c|c|}
\hline Class & $\begin{array}{l}\text { Imaging } \\
\text { Modality }\end{array}$ & NP Type & Composition & Pros & Cons & Ref. \\
\hline \multirow{14}{*}{$\begin{array}{l}\text { Inorganic/or } \\
\text { ganic } \\
\text { hybrids }\end{array}$} & \multirow{8}{*}{$\begin{array}{l}\text { Optical/multi } \\
\text { modal } \\
\text { imaging }\end{array}$} & QDs & $\begin{array}{l}\text { Semiconductor } \\
\text { core/shell arrays }\end{array}$ & $\begin{array}{l}\text { Broad absorption; } \\
\text { narrow emission; } \\
\text { photostability; size } \\
\text { tunability; high } \\
\text { quantum yields }\end{array}$ & $\begin{array}{l}\text { UV } \\
\text { decomposition; } \\
\text { aggregation; } \\
\text { potential } \\
\text { toxicity }\end{array}$ & $\begin{array}{l}7-9 \\
21-40\end{array}$ \\
\hline & & Noble Metal & $\begin{array}{l}\mathrm{Ag} / \mathrm{Au} \mathrm{NPs} \text { or } \\
\text { nanoshells }\end{array}$ & $\begin{array}{l}\text { Size tunability; } \\
\text { sensitivity; NIR } \\
\text { photothermal } \\
\text { therapy }\end{array}$ & $\begin{array}{l}\text { Potential } \\
\text { toxicity; }\end{array}$ & $\begin{array}{l}49-71 ; \\
100-105\end{array}$ \\
\hline & & \multirow[b]{4}{*}{ Metal Oxide } & Irion Oxide & $\begin{array}{l}\text { Conventional MRI } \\
\text { contrast agents }\end{array}$ & $\begin{array}{l}\text { Interference } \\
\text { in Imaging }\end{array}$ & $106-109$ \\
\hline & & & $\begin{array}{l}\text { gold cluster and } \\
\text { gadolinium oxide }\end{array}$ & & & 110 \\
\hline & & & Gd complex & & & 111 \\
\hline & & & $\mathrm{MnO}$ & & & 112 \\
\hline & & Silica NPs & $\begin{array}{l}\text { Ceramic silical } \\
\text { photosensitizers }\end{array}$ & $\begin{array}{l}\text { Facile synthesis; } \\
\text { photostability; } \\
\text { solubility; size } \\
\text { tunability; }\end{array}$ & $\begin{array}{l}\text { aggregation; } \\
\text { ' need } \\
\text { contrast } \\
\text { agents }\end{array}$ & $\begin{array}{l}76-84 ; 1 \\
13-118\end{array}$ \\
\hline & & Molecular Dots & $\begin{array}{l}\text { Calcium } \\
\text { phosphate NPs }\end{array}$ & $\begin{array}{l}\text { Facile synthesis; } \\
\text { photostability; } \\
\text { biodegradability; } \\
\text { photoefficiency }\end{array}$ & $\begin{array}{l}\text { Need } \\
\text { contrast } \\
\text { agents; EPR }\end{array}$ & $85-86$ \\
\hline & \multirow{6}{*}{$\begin{array}{l}\text { Multimodal } \\
\text { Imaging }\end{array}$} & $\begin{array}{l}\text { Upconversion } \\
\text { NPs }\end{array}$ & $\begin{array}{l}\text { Crystalline } \\
\text { nanomaterial }\end{array}$ & $\begin{array}{l}\text { multi-photon } \\
\text { excitation } \\
\text { photoluminescence }\end{array}$ & $\begin{array}{l}\text { Low } \\
\text { optical } \\
\text { brightness }\end{array}$ & $92-95$ \\
\hline & & \multirow{5}{*}{$\begin{array}{l}\text { Carbon-based } \\
\text { NPs }\end{array}$} & Carbon dots & \multirow{5}{*}{$\begin{array}{l}\text { Thermal strength; } \\
\text { antimicrobial ability }\end{array}$} & \multirow{5}{*}{$\begin{array}{l}\text { Poor } \\
\text { solubility; } \\
\text { aggregation; } \\
\text { high } \\
\text { potential for } \\
\text { toxicity }\end{array}$} & $\begin{array}{l}87-91 ; \\
142-146\end{array}$ \\
\hline & & & Fullerenes & & & \\
\hline & & & $\begin{array}{l}\text { CNM/iron oxide } \\
\text { NPs hybrids }\end{array}$ & & & 119 \\
\hline & & & $\begin{array}{l}\text { Graphene } \\
\text { oxide/iron oxide } \\
\text { hybrids }\end{array}$ & & & 120 \\
\hline & & & $\begin{array}{l}\text { Fe core-carbon } \\
\text { shell }\end{array}$ & & & 1251 \\
\hline \multirow[b]{3}{*}{$\begin{array}{l}\text { Organic } \\
\text { NPs }\end{array}$} & \multirow{3}{*}{$\begin{array}{l}\text { Multimodal } \\
\text { Imaging }\end{array}$} & Biological NPs & $\begin{array}{l}\text { Naturally derived } \\
\text { polymers }\end{array}$ & $\begin{array}{l}\text { Biocompatibility; } \\
\text { flexibility; } \\
\text { biodegra dability; }\end{array}$ & $\begin{array}{l}\text { Mechanical } \\
\text { weakness; } \\
\text { difficulty in } \\
\text { size control }\end{array}$ & $139-141$ \\
\hline & & $\begin{array}{l}\text { Polymer } \\
\text { Nanospheres }\end{array}$ & $\begin{array}{l}\text { Repeated linear or } \\
\text { branched units }\end{array}$ & $\begin{array}{l}\text { Biodegradability; } \\
\text { flexibility; size } \\
\text { tunability }\end{array}$ & $\begin{array}{l}\text { Need } \\
\text { contrast } \\
\text { agents }\end{array}$ & $\begin{array}{l}123-125 ; \\
155-158\end{array}$ \\
\hline & & Liposomes & $\begin{array}{l}\text { Phospholipid } \\
\text { bilayers }\end{array}$ & $\begin{array}{l}\text { Conventi onal drug } \\
\text { delivery vehicles; } \\
\text { large payload; EPR }\end{array}$ & $\begin{array}{l}\text { Need } \\
\text { contrast } \\
\text { agents; poor } \\
\text { stability; } \\
\text { opsonization }\end{array}$ & 154 \\
\hline
\end{tabular}


12. M. M. Mahan and A. L. Doiron, J. Nanomater, 2018, 2018, 15.

13. K. S. Lee and M. A. El-Sayed, J. Phys. Chem. B, 2006, 110, 19220-19225.

14. V. Kravets, Z. Almemar, K. Jiang, K. Culhane, R. Machado, G. Hagen, A. Kotko, I. Dmytruk, K. Spendier and A. Pinchuk, Nanoscale Res. Lett., 2016, 11,30 .

15. C. Sun, J. S. Lee and M. Zhang, Adv. Drug. Deliv. Rev., 2008, 60, 12521265 .

16. J. H. Lee, J. W. Kim and J. Cheon, Mol.Cells, 2013, 35, 274-284.

17. D. E. Sosnovik, M. Nahrendorf and R. Weissleder, Basic. Res. Cardiol., 2008, 103, 122-130.

18. Z. R. Stephen, F. M. Kievit and M. Zhang, Mater. Today (Kidlington), 2011, 14, 330-338.

19. T. H. Shin, Y. Choi, S. Kim and J. Cheon, Chem. Soc.Rev., 2015, 44, 45014516.

20. Z. Wang, R. Qiao, N. Tang, Z. Lu, H. Wang, Z. Zhang, X. Xue, Z. Huang, S. Zhang, G. Zhang and Y. Li, Biomaterials, 2017, 127, 25-35.

21. K. E. Sapsford, T. Pons, I. L. Medintz and H. Mattoussi, Sensor. (Basel, Switzerland), 2006, 6, 925-953.

22. J. Li and J. J. Zhu, Analyst, 2013, 138, 2506-2515.

23. A. Shiohara, A. Hoshino, K. Hanaki, K. Suzuki and K. Yamamoto, Microbiol. Immunol., 2004, 48, 669-675.

24. J. K. Jaiswal, E. R. Goldman, H. Mattoussi and S. M. Simon, Nat. Methods., 2004, 1, 73-78.

25. I. V. Martynenko, A. P. Litvin, F. Purcell-Milton, A. V. Baranov, A. V. Fedorov and Y. K. Gun'ko, J. Mater. Chem. B, 2017, 5, 6701-6727.

26. A. Quarta, A. Ragusa, S. Deka, C. Tortiglione, A. Tino, R. Cingolani and T. Pellegrino, Langmuir, 2009, 25, 12614-12622.

27. D. J. Bharali, D. W. Lucey, H. Jayakumar, H. E. Pudavar and P. N. Prasad, J. Am. Chem. Soc., 2005, 127, 11364-11371.

28. C. R. Patra, Y. Jing, Y. H. Xu, R. Bhattacharya, D. Mukhopadhyay, J. F. Glockner, J. P. Wang and P. Mukherjee, Cancer Nanotechnol., 2010, 1, 1318 .

29. Y. Zhu, H. Hong, Z. P. Xu, Z. Li and W. Cai, Curr. Mol. Med., 2013, 13, 1549-1567.

30. T. A. Zdobnova, E. N. Lebedenko and C. Deyev Scapital Em, Acta. Naturae, 2011, 3, 29-47.

31. C. P. Parungo, Y. L. Colson, S. W. Kim, S. Kim, L. H. Cohn, M. G. Bawendi and J. V. Frangioni, Chest, 2005, 127, 1799-1804.

32. J. R. Slotkin, L. Chakrabarti, H. N. Dai, R. S. Carney, T. Hirata, B. S. Bregman, G. I. Gallicano, J. G. Corbin and T. F. Haydar, Dev. Dyn., 2007, 236, 3393-3401.

33. J. V. Frangioni, S. W. Kim, S. Ohnishi, S. Kim and M. G. Bawendi, Methods. Mol. Biol., 2007, 374, 147-159.

34. P. Zhao, Q. Xu, J. Tao, Z. Jin, Y. Pan, C. Yu and Z. Yu, Wiley Interdiscip. Rev. Nanomed. Nanobiotechnol., 2018, 10, e1483.

35. Q. Ma and X. Su, Analyst, 2010, 135, 1867-1877.

36. M. Helle, E. Cassette, L. Bezdetnaya, T. Pons, A. Leroux, F. Plenat, F. Guillemin, B. Dubertret and F. Marchal, Plos One, 2012, 7, e44433.

37. N. Y. Morgan, S. English, W. Chen, V. Chernomordik, A. Russo, P. D. Smith and A. Gandjbakhche, Acad. Radiol., 2005, 12, 313-323.

38. J. Chen, Y. Pei, Z. Chen and J. Cai, Micron, 2010, 41, 198-202.

39. J. Fan, X. Lu, S. Liu and L. Zhong, Nanoscale Res. Lett., 2015, 10, 419.

40. J. Xu, K. F. Tehrani and P. Kner, ACS Nano, 2015, 9, 2917-2925.

41. K. S. Park, J. Tae, B. Choi, Y. S. Kim, C. Moon, S. H. Kim, H. S. Lee, J. Kim, J. Park, J. H. Lee, J. E. Lee, J. W. Joh and S. Kim, Nanomedicine, 2010, 6, 263-276.

42. S. Santra, B. Liesenfeld, C. Bertolino, D. Dutta, Z. Cao, W. Tan, B. M. Moudgil and R. A. Mericle, J. Lumin., 2006, 117, 75-82.

43. Z. Li, Y. Wang, J. Wang, Z. Tang, J. G. Pounds and Y. Lin, Anal. Chem., 2010, 82, 7008-7014

44. M. Fang, C. W. Peng, D. W. Pang and Y. Li, Cance. Biol. Med., 2012, 9, 151-163.

45. Y. Xing, A. M. Smith, A. Agrawal, G. Ruan and S. Nie, Int. J. Nanomed,, 2006, 1, 473-481.

46. N. Durisic, A. I. Bachir, D. L. Kolin, B. Hebert, B. C. Lagerholm, P. Grutter and P. W. Wiseman, Biophys. J., 2007, 93, 1338-1346.

47. S. F. Lee and M. A. Osborne, Chemphyschem, 2009, 10, 2174-2191.

48. J. J. Peterson and D. J. Nesbitt, Nano. Lett., 2009, 9, 338-345.
49. S. Lee, E. J. Cha, K. Park, S. Y. Lee, J. K. Hong, I. C. Sun, S. Y. Kim, K. Choi, I. C. Kwon, K. Kim and C. H. Ahn, Angew. Chem. Int. Ed. Engl., 2008, 47, 2804-2807.

50. L. Shang, J. Yin, J. Li, L. Jin and S. Dong, Biosens Bioelectron., 2009, 25, 269-274.

51. W. Li and X. Chen, Nanomed. (Lond), 2015, 10, 299-320.

52. D. C. Adler, S. W. Huang, R. Huber and J. G. Fujimoto, Opt. Express., 2008, 16, 4376-4393.

53. S. E. Skrabalak, J. Chen, Y. Sun, X. Lu, L. Au, C. M. Cobley and Y. Xia, Acc. Chem. Res., 2008, 41, 1587-1595.

54. S. H. Christiansen, M. Becker, S. Fahlbusch, J. Michler, V. Sivakov, G. Andra and R. Geiger, Nanotechnology, 2007, 18, 035503.

55. W. Lu, A. K. Singh, S. A. Khan, D. Senapati, H. Yu and P. C. Ray, J. Am. Chem. Soc., 2010, 132, 18103-18114.

56. T. Huang and X. H. Nancy Xu, J. Mater. Chem., 2010, 20, 9867-9876.

57. K. J. Lee, L. M. Browning, T. Huang, F. Ding, P. D. Nallathamby and X. H. Xu, Anal. Bioanal. Chem., 2010, 397, 3317-3328.

58. F. Ding, K. J. Lee, A. Vahedi-Faridi, T. Huang and X. H. Xu, Anal. Bioanal. Chem., 2011, 400, 223-235.

59. L. M. Browning, K. J. Lee, P. K. Cherukuri, T. Huang, P. Songkiatisak, S. Warren and X. H. N. Xu, Analyst, 2018, 143, 1599-1608.

60. X. N. Xu, K. J. L. Lee, T. Huang, N. D. Prakash and F. Ding, Abs. of Pittcon on Anal. Chem. and Appl. Spectrosc., 2016, 1070.

61. J. K. Lee, B. M. Lauren, T. Huang, F. Ding and X. N. Xu, Abs. of Pittcon on Anal. Chem. and Appl. Spectrosc., 2010.

62. F. Ding, Old Dominion University, 2013.

63. F. Ding, K. J. Lee, A. Vahedi-Faridi, H. Yoneyama, C. J. Osgood and X. H. Xu, Analyst, 2014, 139, 3088-3096.

64. X. N. Xu, P. Songkiatisak, P. Cherukuri, F. Ding and T. Huang, Abs. of Papers of the ACS, 2018, 256.

65. P. D. Nallathamby, K. J. Lee, T. Desai and X. H. Xu, Biochemistry, 2010, 49, 5942-5953.

66. X. N. Xu, P. K. Cherukuri, K. J. L. Lee, T. H. Huang and F. Ding, Abs of Papers of SciX Conf., 2016.

67. P. Songkiatisak, P. Cherukuri, A. Poudel and X. N. Xu, Abs of Papers of the ACS, 2017, 254

68. A. Korell, P. Songkiatisak, A. Poudel, S. Phan and X. N. Xu, Abs of Papers of the ACS, 2017, 254.

69. T. Huang, P. D. Nallathamby and X. H. Xu, J. Am. Chem. Soc., 2008, 130, 17095-17105.

70. T. Huang and X. H. Nancy Xu, Nanoscale, 2011, 3, 3567-3572.

71. T. Huang, L. M. Browning and X. H. Xu, Nanoscale, 2012, 4, 2797-2812.

72. X. N. Xu, P. Songkiatisak, P. Cherukuri and A. Poudel, Abs of Papers of the ACS, 2017, 254.

73. X. H. Xu, P. K. Cherukuri, P. Songkiatisak, S. Warren and T. Huang, Abs of Papers of the ACS, 2015, 250.

74. X. N. Xu, F. Ding, J. K. Lee, T. Huang and D. P. Nallathamby, Abs of Pittcon on Anal. Chem. and Appl. Spectrosc., 2015, 1060.

75. X. N. Xu, J. K. Lee, T. Huang, D. P. Nallathamby and F. Ding, Abs. of Pittcon on Anal. Chem. and Appl. Spectrosc., 2014.

76. V. Cauda, A. Schlossbauer, J. Kecht, A. Zurner and T. Bein, J. Am. Chem. Soc., 2009, 131, 11361-11370.

77. H. L. Kim, S. B. Lee, H. J. Jeong and D. W. Kim, RSC Advances, 2014, 4, 31318-31322.

78. H. Tan, Y. Zhang, M. Wang, Z. Zhang, X. Zhang, A. M. Yong, S. Y. Wong, A. Y. Chang, Z. K. Chen, X. Li, M. Choolani and J. Wang, Biomaterials, 2012, 33, 237-246.

79. L. Cai, Z. Z. Chen, M. Y. Chen, H. W. Tang and D. W. Pang, Biomaterials, 2013, 34, 371-381

80. J. Kim, L. Cao, D. Shvartsman, E. A. Silva and D. J. Mooney, Nano Lett., 2011, 11, 694-700.

81. X. Le Guével, B. Hötzer, G. Jung and M. Schneider, J. Mater. Chem., 2011, 21, 2974-2981.

82. S. Shi, F. Chen, S. Goel, S. A. Graves, H. Luo, C. P. Theuer, J. W. Engle and W. Cai, Nano-Micro Lett., 2018, 10, 65.

83. L. Tang and J. Cheng, Nano Today, 2013, 8, 290-312.

84. B. G. Cha and J. Kim, Wiley Interdiscip. Rev. Nanomed. Nanobiotechnol., 2019, 11, e1515. 
85. M. Zhang, L. Zhang, Y. Chen, L. Li, Z. Su and C. Wang, Chem. Sci., 2017, 8, 8067-8077.

86. G. Li, Y. Chen, L. Zhang, M. Zhang, S. Li, L. Li, T. Wang and C. Wang, Nano-Micro Lett., 2017, 10, 7.

87. S. Khan, N. C. Verma, Chethana and C. K. Nandi, ACS Appl. Nano Mater. 2018, 1, 483-487.

88. T. S. Atabaev, Z. Piao and A. Molkenova, J. Funct. Biomater, 2018, 9.

89. L. Cao, X. Wang, M. J. Meziani, F. Lu, H. Wang, P. G. Luo, Y. Lin, B. A. Harruff, L. M. Veca, D. Murray, S. Y. Xie and Y. P. Sun, J. Am. Chem.Soc., 2007, 129, 11318-11319.

90. H. Wang, J. Shen, Y. Li, Z. Wei, G. Cao, Z. Gai, K. Hong, P. Banerjee and S. Zhou, Biomater. Sci-uk, 2014, 2, 915-923.

91. P. Y. Liyanage, R. M. Graham, R. R. Pandey, C. C. Chusuei, K. J. Mintz, Y. Zhou, J. K. Harper, W. Wu, A. H. Wikramanayake, S. Vanni and R. M. Leblanc, Bioconj. Chem., 2019, 30, 111-123.

92. C. Wang, L. Cheng and Z. Liu, Biomaterials, 2011, 32, 1110-1120.

93. M. Guan, H. Dong, J. Ge, D. Chen, L. Sun, S. Li, C. Wang, C. Yan, P. Wang and C. Shu, Npg Asia Mater., 2015, 7, e205.

94. J. Zhou, Q. Liu, W. Feng, Y. Sun and F. Li, Chem. Rev., 2015, 115, 395-465.

95. K. Zhang, Q. Zhao, S. Qin, Y. Fu, R. Liu, J. Zhi and C. Shan, J. Colloid. Interface. Sci., 2019, 537, 316-324.

96. D. P. Cormode, P. C. Naha and Z. A. Fayad, Contrast Media Moli., 2014, 9, 37-52.

97. X. Cai, W. Li, C. H. Kim, Y. Yuan, L. V. Wang and Y. Xia, ACS Nano, 2011, 5, 9658-9667.

98. J. Estelrich, M. J. Sanchez-Martin and M. A. Busquets, Int. J. Nanomed., 2015, 10, 1727-1741.

99. J. Liu, A. L. Levine, J. S. Mattoon, M. Yamaguchi, R. J. Lee, X. Pan and T. J. Rosol, Phys. Med. Biol., 2006, 51, 2179-2189.

100. D. P. Cormode, E. Roessl, A. Thran, T. Skajaa, R. E. Gordon, J. P. Schlomka, V. Fuster, E. A. Fisher, W. J. Mulder, R. Proksa and Z. A. Fayad, Radiology, 2010, 256, 774-782.

101. T. Nakagawa, K. Gonda, T. Kamei, L. Cong, Y. Hamada, N. Kitamura, H. Tada, T. Ishida, T. Aimiya, N. Furusawa, Y. Nakano and N. Ohuchi, Sci. Technol. Adv. Mater., 2016, 17, 387-397.

102. A. Silvestri, V. Zambelli, A. M. Ferretti, D. Salerno, G. Bellani and L. Polito, Contrast Media Moli., 2016, 11, 405-414.

103. F. Aziz, A. Ihsan, A. Nazir, I. Ahmad, S. Z. Bajwa, A. Rehman, A. Diallo and W. S. Khan, Int. J. Nanomed., 2017, 12, 1555-1563.

104. P. C. Naha, K. C. Lau, J. C. Hsu, M. Hajfathalian, S. Mian, P. Chhour, L. Uppuluri, E. S. McDonald, A. D. Maidment and D. P. Cormode, Nanoscale, 2016, 8, 13740-13754

105. X. Li, C. Wang, H. Tan, L. Cheng, G. Liu, Y. Yang, Y. Zhao, Y. Zhang, Y. Li, C. Zhang, Y. Xiu, D. Cheng and H. Shi, Biomaterials, 2016, 108, 7180

106. J. K. Wang, Y. Y. Zhou, S. J. Guo, Y. Y. Wang, C. J. Nie, H. L. Wang, J. L. Wang, Y. Zhao, X. Y. Li and X. J. Chen, Mater. Sci. Eng. C Mater. Biol. Appl., 2017, 76, 944-950.

107. Y. Wei, R. Liao, A. A. Mahmood, H. Xu and Q. Zhou, Acta. Biomater, 2017, 55, 194-203.

108. A. Tomitaka, H. Arami, A. Raymond, A. Yndart, A. Kaushik, R. D. Jayant, Y. Takemura, Y. Cai, M. Toborek and M. Nair, Nanoscale, 2017, 9, 764773.

109. Z. Sun, K. Cheng, F. Wu, H. Liu, X. Ma, X. Su, Y. Liu, L. Xia and Z. Cheng, Nanoscale, 2016, 8, 19644-19653.

110. C. Xu, Y. Wang, C. Zhang, Y. Jia, Y. Luo and X. Gao, Nanoscale, 2017, 9, $4620-4628$

111. J. S. Ananta, B. Godin, R. Sethi, L. Moriggi, X. Liu, R. E. Serda, R. Krishnamurthy, R. Muthupillai, R. D. Bolskar, L. Helm, M. Ferrari, L. J. Wilson and P. Decuzzi, Nat. Nanotechnol., 2010, 5, 815-821.

112. M. J. Baek, J. Y. Park, W. Xu, K. Kattel, H. G. Kim, E. J. Lee, A. K. Patel, J. J. Lee, Y. Chang, T. J. Kim, J. E. Bae, K. S. Chae and G. H. Lee, ACS Appl. Mater. Interfaces., 2010, 2, 2949-2955.

113. H. S. Choi, W. Liu, P. Misra, E. Tanaka, J. P. Zimmer, B. Itty Ipe, M. G. Bawendi and J. V. Frangioni, Nat. Biotechnol., 2007, 25, 1165-1170.

114. J. H. Park, L. Gu, G. von Maltzahn, E. Ruoslahti, S. N. Bhatia and M. J. Sailor, Nat. Mater, 2009, 8, 331-336.

115. X. Y. Zheng, J. Pellico, A. A. Khrapitchev, N. R. Sibson and J. J. Davis,
Nanoscale, 2018, 10, 21041-21045.

116. V. R. N, H. S. Han, H. Lee, V. Q. Nguyen, S. Jeon, D. W. Jung, J. Lee, G. R. Yi and J. H. Park, Nanoscale, 2018, 10, 9616-9627.

117. C. Liu, H. Yu, Q. Li, C. Zhu and Y. Xia, ACS Appl. Mater. Inter, 2018, 10, 16291-16298.

118. D. Lee, S. Beack, J. Yoo, S.-K. Kim, C. Lee, W. Kwon, S. K. Hahn and C. Kim, Adv. Funct. Mater., 2018, 28, 1800941.

119. Y. Liu, T. C. Hughes, B. W. Muir, L. J. Waddington, T. R. Gengenbach, C. D. Easton, T. M. Hinton, B. A. Moffat, X. Hao and J. Qiu, Biomaterials, 2014, 35, 378-386

120. C. Xu, S. Shi, L. Feng, F. Chen, S. A. Graves, E. B. Ehlerding, S. Goel, H. Sun, C. G. England, R. J. Nickles, Z. Liu, T. Wang and W. Cai, Nanoscale, 2016, 8, 12683-12692.

121. R. P. Chaudhary, K. Kangasniemi, M. Takahashi, S. K. Mohanty and A. R. Koymen, J. Funct. Biomater, 2017, 8

122. O. N. Metelkina, R. W. Lodge, P. G. Rudakovskaya, V. M. Gerasimov, C H. Lucas, I. S. Grebennikov, I. V. Shchetinin, A. G. Savchenko, G. E. Pavlovskaya, G. A. Rance, M. del Carmen Gimenez-Lopez, A. N. Khlobystov and A. G. Majouga, J. Mater. Chem. C, 2017, 5, 2167-2174.

123. J. Zhang, Y. Huang, D. Wang, A. C. Pollard, Z. Chen and E. Egap, $J$ Mater. Chem. C, 2017, 5, 5685-5692.

124. X. Hu, F. Lu, L. Chen, Y. Tang, W. Hu, X. Lu, Y. Ji, Z. Yang, W. Zhang, C. Yin, W. Huang and Q. Fan, ACS Appl. Mater. Inter, 2017, 9, 30458-30469.

125. T. Yildiz, R. Gu, S. Zauscher and T. Betancourt, Int. J. Nanomed., 2018, 13 6961-6986.

126. P. Baptista, E. Pereira, P. Eaton, G. Doria, A. Miranda, I. Gomes, P. Quaresma and R. Franco, Anal. Bioanal. Chem., 2008, 391, 943-950.

127. E. Boisselier and D. Astruc, Chem. Soc. Rev., 2009, 38, 1759-1782.

128. Y. Li, H. J. Schluesener and S. Xu, Gold Bull., 2010, 43, 29-41.

129. L. He, M. D. Musick, S. R. Nicewarner, F. G. Salinas, S. J. Benkovic, M. J. Natan and C. D. Keating, J. Am. Chem. Soc. 2000, 122, 9071-9077.

130. J. Spadavecchia, A. Barras, J. Lyskawa, P. Woisel, W. Laure, C. M. Pradier, R. Boukherroub and S. Szunerits, Anal. Chem., 2013, 85, 3288-3296.

131. S. Andreescu and L. A. Luck, Anal. Biochem., 2008, 375, 282-290.

132. B. K. Jena and C. R. Raj, Anal. Chem., 2006, 78, 6332-6339.

133. Y. Xu, C. Hu and S. Hu, Sensor. Actuat. B-Chem., 2008, 130, 816-822.

134. C. Y. Liu and J. M. Hu, Biosens. Bioelectron., 2009, 24, 2149-2154.

135. J. C. Claussen, A. Kumar, D. B. Jaroch, M. H. Khawaja, A. B. Hibbard, D. M. Porterfield and T. S. Fisher, Adv. Funct. Mater., 2012, 22, 3399-3405.

136. E. Petryayeva and W. R. Algar, Analyst, 2015, 140, 4037-4045.

137. S. Cui, S. Xu, H. Song, W. Xu, X. Chen, D. Zhou, Z. Yin and W. Han, RSC $A d v ., 2015, \mathbf{5}, 99099-99106$

138. Z. M. Zhou, Z. Feng, J. Zhou, B. Y. Fang, Z. Y. Ma, B. Liu, Y. D. Zhao and X. B. Hu, Sensor. Actuat. B-Chem., 2015, 210, 158-164.

139. J. M. Chan, L. Zhang, K. P. Yuet, G. Liao, J. W. Rhee, R. Langer and O. C. Farokhzad, Biomaterials, 2009, 30, 1627-1634.

140. T. Sun, J. H. Dou, S. Liu, X. Wang, X. Zheng, Y. Wang, J. Pei and Z. Xie, ACS Appl. Mater. Inter., 2018, 10, 7919-7926.

141. D. S. Chauhan, A. B. Bukhari, G. Ravichandran, R. Gupta, L. George, R Poojari, A. Ingle, A. K. Rengan, A. Shanavas, R. Srivastava and A. De, Sci. Rep-UK, 2018, 8, 16673

142. S. Kim, Y. Choi, G. Park, C. Won, Y. J. Park, Y. Lee, B. S. Kim and D. H Min, Nano Res., 2017, 10, 503-519.

143. S. Li, D. Amat, Z. Peng, S. Vanni, S. Raskin, G. De Angulo, A. M. Othman, R. M. Graham and R. M. Leblanc, Nanoscale, 2016, 8, 1666216669

144. X. L. Guo, Z. Y. Ding, S. M. Deng, C. C. Wen, X. C. Shen, B. P. Jiang and H. Liang, Carbon, 2018, 134, 519-530.

145. M. Lan, S. Zhao, Z. Zhang, L. Yan, L. Guo, G. Niu, J. Zhang, J. Zhao, H. Zhang, P. Wang, G. Zhu, C. S. Lee and W. Zhang, Nano Res., 2017, 10, 3113-3123.

146. R. Mohammadinejad, A. Dadashzadeh, S. Moghassemi, M. Ashrafizadeh, A. Dehshahri, A. Pardakhty, H. Ali Sassan, S. Mojtaba Sohrevardi and A. Mandegary, J. Adv. Res., 2019.

147. Y. Yang, F. Liu, X. Liu and B. Xing, Nanoscale, 2013, 5, 231-238.

148. Z. Zhao, Y. Han, C. Lin, D. Hu, F. Wang, X. Chen, Z. Chen and N. Zheng, Chem. Asian. J., 2012, 7, 830-837.

149. M. E. Lim, Y. L. Lee, Y. Zhang and J. J. Chu, Biomaterials, 2012, 33, 
1912-1920.

150. S. Cui, D. Yin, Y. Chen, Y. Di, H. Chen, Y. Ma, S. Achilefu and Y. Gu, $A C S$ Nano, 2013, 7, 676-688.

151. Y. Yang and D. Cui, in Gastric Cancer Prewarning and Early Diagnosis System, ed. D. Cui, Springer Netherlands, Dordrecht, 2017, pp. 239-270.

152. X. Wang, R. R. Valiev, T. Y. Ohulchanskyy, H. Agren, C. Yang and G. Chen, Chem. Soc. Rev., 2017, 46, 4150-4167.

153. H. Qiu, M. Tan, T. Y. Ohulchanskyy, J. F. Lovell and G. Chen, Nanomater. (Basel), 2018, 8.

154. D. W. Northfelt, B. J. Dezube, J. A. Thommes, B. J. Miller, M. A. Fischl, A. Friedman-Kien, L. D. Kaplan, C. Du Mond, R. D. Mamelok and D. H. Henry, J. Clin. Oncol., 1998, 16, 2445-2451.

155. J. Kreuter, R. N. Alyautdin, D. A. Kharkevich and A. A. Ivanov, Brain. Res., 1995, 674, 171-174.

156. J. M. Koziara, P. R. Lockman, D. D. Allen and R. J. Mumper, J. Nanosci. Nanotechnol., 2006, 6, 2712-2735.

157. M. Liu, H. Li, G. Luo, Q. Liu and Y. Wang, Arch. Pharm. Re.s, 2008, 31, 547-554.

158. W. Geldenhuys, T. Mbimba, T. Bui, K. Harrison and V. Sutariya, J. Drug. Target., 2011, 19, 837-845.

159. A. Elder, R. Gelein, V. Silva, T. Feikert, L. Opanashuk, J. Carter, R. Potter, A. Maynard, Y. Ito, J. Finkelstein and G. Oberdorster, Environ. Health. Perspect., 2006, 114, 1172-1178.

160. H. Liang, L. He, B. Zhou, B. Li and J. Li, Colloid. Surfaces.B, 2017, 156, 19-28.

161. L. Wang, J. Huang, H. Chen, H. Wu, Y. Xu, Y. Li, H. Yi, Y. A. Wang, L. Yang and H. Mao, ACS Nano, 2017, 11, 4582-4592.

162. D. Yang, L. Feng, C. A. Dougherty, K. E. Luker, D. Chen, M. A. Cauble, M. M. Banaszak Holl, G. D. Luker, B. D. Ross, Z. Liu and H. Hong, Biomaterials, 2016, 104, 361-371.

163. X. Suo, B. N. Eldridge, H. Zhang, C. Mao, Y. Min, Y. Sun, R. Singh and X. Ming, ACS Appl. Mater. Int., 2018, 10, 33464-33473.

164. A. Sargazi, N. Kamali, F. Shiri and M. Heidari Majd, Artif. Cell. Blood. Sub., 2018, 46, 500-509.

165. Y. W. Chen, Y. L. Su, S. H. Hu and S. Y. Chen, Adv. Drug. Del. Rev., 2016, 105, 190-204.

166. H. Moon, D. Kumar, H. Kim, C. Sim, J. H. Chang, J. M. Kim and D. K. Lim, ACS Nano, 2015, 9, 2711-2719.

167. Z. Sobhani, M. A. Behnam, F. Emami, A. Dehghanian and I. Jamhiri, Int. J. Nanomed., 2017, 12, 4509-4517.

168. M. H. Bahreyni-Toosi, M. H. Zare, A. Ale-Davood, M. T. Shakeri and S. Soudmand, J. Biomed. Phys. Eng., 2017, 7, 317-332.

169. Y. Wang, K. C. Black, H. Luehmann, W. Li, Y. Zhang, X. Cai, D. Wan, S. Y. Liu, M. Li, P. Kim, Z. Y. Li, L. V. Wang, Y. Liu and Y. Xia, ACS Nano, 2013, 7, 2068-2077.

170. S. Wang, P. Huang, L. Nie, R. Xing, D. Liu, Z. Wang, J. Lin, S. Chen, G. Niu, G. Lu and X. Chen, Adv. Mater, 2013, 25, 3055-3061.

171. S. Tang, M. Chen and N. Zheng, Small, 2014, 10, 3139-3144.

172. X. Huang, S. Tang, X. Mu, Y. Dai, G. Chen, Z. Zhou, F. Ruan, Z. Yang and N. Zheng, Nat. Nanotechno., 2011, 6, 28-32.

173. B. Li, Q. Wang, R. Zou, X. Liu, K. Xu, W. Li and J. Hu, Nanoscale, 2014, 6, 3274-3282

174. Q. Tian, J. Hu, Y. Zhu, R. Zou, Z. Chen, S. Yang, R. Li, Q. Su, Y. Han and X. Liu, J. Am. Chem. Soc., 2013, 135, 8571-8577.

175. P. Pedrosa, R. Mendes, R. Cabral, L. M. D. R. S. Martins, P. V. Baptista and A. R. Fernandes, Sci. Rep., 2018, 8, 11429.

176. Z. Chen, J. Chi, Y. Sun and Y. Sun, Artificial Cells, Nanomed. Biotechno., 2018, 46, 817-830.

177. G. Lopez-Berestein, V. Fainstein, R. Hopfer, K. Mehta, M. P. Sullivan, M. Keating, M. G. Rosenblum, R. Mehta, M. Luna, E. M. Hersh and et al., J. Infect. Dis., 1985, 151, 704-710.

178. T. Yazeji, B. Moulari, A. Beduneau, V. Stein, D. Dietrich, Y. Pellequer and A. Lamprecht, Drug. Deliv., 2017, 24, 811-817.

179. K. Letchmanan, S. C. Shen, W. K. Ng, P. Kingshuk, Z. Shi, W. Wang and R. B. H. Tan, J. Mech. Behav. Biomed. Mater, 2017, 72, 163-170.

180. Y. Li, H. Hu, Q. Zhou, Y. Ao, C. Xiao, J. Wan, Y. Wan, H. Xu, Z. Li and X. Yang, ACS Appl. Mater. Int., 2017, 9, 19215-19230.

181. X. Xue, L. R. Wang, Y. Sato, Y. Jiang, M. Berg, D. S. Yang, R. A. Nixon and X. J. Liang, Nano Lett., 2014, 14, 5110-5117.

182. C. Saraiva, L. Ferreira and L. Bernardino, Neurogenesis (Austin), 2016, 3, e1256855.

183. J. McMasters, S. Poh, J. B. Lin and A. Panitch, J. Control. Release, 2017, 258, $161-170$

184. L. Huang, T. Dai, Y. Xuan, G. P. Tegos and M. R. Hamblin, Antimicrob. Agents Ch., 2011, 55, 3432-3438.

185. F. Ding, P. Songkiatisak, P. K. Cherukuri, T. Huang and X. H. N. Xu, ACS Omega, 2018, 3, 1231-1243.

186. D. Makarovsky, L. Fadeev, B. B. Salam, E. Zelinger, O. Matan, J. Inbar, E. Jurkevitch, M. Gozin and S. Burdman, Appl. Environ. Microbiol., 2018, 84.

187. B. Kim, H.-B. Pang, J. Kang, J.-H. Park, E. Ruoslahti and M. J. Sailor, Nat. Commun., 2018, 9, 1969.

188. S. Yang, X. Han, Y. Yang, H. Qiao, Z. Yu, Y. Liu, J. Wang and T. Tang, ACS Appl. Mater. Inter., 2018, 10, 14299-14311.

189. P. Yuan, X. Ding, Y. Y. Yang and Q. H. Xu, Adv. Healthc. Mater., 2018, 7, e1701392.

190. X. Zhu, A. F. Radovic-Moreno, J. Wu, R. Langer and J. Shi, Nano Today, 2014, 9, 478-498.

191. C. I. Colino, C. G. Millan and J. M. Lanao, Int. J. Mol. Sci., 2018, 19

192. W. Cha, R. Fan, Y. Miao, Y. Zhou, C. Qin, X. Shan, X. Wan and J. Li, Molecules, 2017, 22

193. R. Landsiedel, M. D. Kapp, M. Schulz, K. Wiench and F. Oesch, Mutat Res., 2009, 681, 241-258.

194. K. J. Lee, P. D. Nallathamby, L. M. Browning, C. J. Osgood and X. H. Xu, ACS Nano, 2007, 1, 133-143.

195. L. M. Browning, K. J. Lee, T. Huang, P. D. Nallathamby, J. E. Lowman and X. H. Xu, Nanoscale, 2009, 1, 138-152.

196. K. J. Lee, L. M. Browning, P. D. Nallathamby, T. Desai, P. K. Cherukuri and X. H. Xu, Chem. Res. Toxicol., 2012, 25, 1029-1046.

197. P. D. Nallathamby and X. H. Xu, Nanoscale, 2010, 2, 942-952.

198. L. Chen, R. A. Yokel, B. Hennig and M. Toborek, J. Neuroimmune Pharm., 2008, 3, 286-295.

199. E. Radziun, J. Dudkiewicz Wilczynska, I. Ksiazek, K. Nowak, E. L. Anuszewska, A. Kunicki, A. Olszyna and T. Zabkowski, Toxicol. In. Vitro., 2011, 25, 1694-1700.

200. E. E. Connor, J. Mwamuka, A. Gole, C. J. Murphy and M. D. Wyatt, Small, 2005, 1, 325-327.

201. V. Aruoja, H. C. Dubourguier, K. Kasemets and A. Kahru, Sci. Total Environ., 2009, 407, 1461-1468.

202. S. Naqvi, M. Samim, M. Abdin, F. J. Ahmed, A. Maitra, C. Prashant and A. K. Dinda, Int. J. Nanomed., 2010, 5, 983-989.

203. A. Magrez, S. Kasas, V. Salicio, N. Pasquier, J. W. Seo, M. Celio, S Catsicas, B. Schwaller and L. Forro, Nano Lett., 2006, 6, 1121-1125.

204. A. Dhawan, J. S. Taurozzi, A. K. Pandey, W. Shan, S. M. Miller, S. A Hashsham and V. V. Tarabara, Environ. Sci. Technol., 2006, 40, 7394-7401.

205. E. J. Park and K. Park, Toxicol. Lett., 2009, 184, 18-25.

206. N. Grabowski, H. Hillaireau, J. Vergnaud, N. Tsapis, M. Pallardy, S Kerdine-Romer and E. Fattal, Int. J. Pharm., 2015, 482, 75-83.

207. A. Pena, B. Murat, M. Trueba, M. A. Ventura, N. C. Wo, H. H. Szeto, L. L. Cheng, S. Stoev, G. Guillon and M. Manning, J. Med. Chem., 2007, 50, 835-847.

208. H. Bahadar, F. Maqbool, K. Niaz and M. Abdollahi, Iran Biomed J, 2016 , 20, 1-11.

209. A. Kroll, M. H. Pillukat, D. Hahn and J. Schnekenburger, Eur. J. Pharm. Biopharm., 2009, 72, 370-377.

210. K. Donaldson, P. J. Borm, V. Castranova and M. Gulumian, Part. Fibre Toxicol., 2009, 6, 13

211. W. I. Hagens, A. G. Oomen, W. H. de Jong, F. R. Cassee and A. J. Sips, Regul. Toxicol. Pharmacol., 2007, 49, 217-229.

212. A. Pourmand and M. Abdollahi, Daru, 2012, 20, 95.

213. N. A. Monteiro-Riviere, A. O. Inman and L. W. Zhang, Toxicol. Appl. Pharmacol., 2009, 234, 222-235.

214. L. Yang and D. J. Watts, Toxicol. Lett., 2005, 158, 122-132.

215. M. J. Clift, B. Rothen-Rutishauser, D. M. Brown, R. Duffin, K. Donaldson, L. Proudfoot, K. Guy and V. Stone, Toxicol. Appl. Pharmacol., 2008, 232, 418-427. 
216. C. Fernandez-Ponce, J. P. Munoz-Miranda, D. M. de Los Santos, E. Aguado, F. Garcia-Cozar and R. Litran, J. Nanopart. Res., 2018, 20, 305.

217. S. T. Kim, K. Saha, C. Kim and V. M. Rotello, Acc. Chem. Res., 2013, 46,
681-691.

218. M. Cho, W. S. Cho, M. Choi, S. J. Kim, B. S. Han, S. H. Kim, H. O. Kim, Y. Y. Sheen and J. Jeong, Toxicol. Lett., 2009, 189, 177-183. 